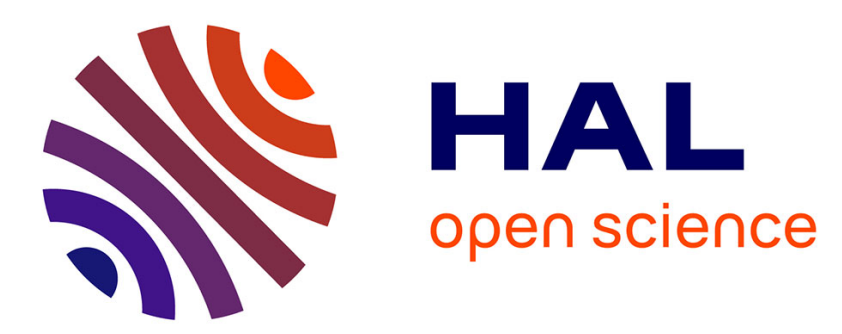

\title{
FeBr2-Catalyzed Bulk ATRP Promoted by Simple Inorganic Salts
}

Jirong Wang, Jianyu Han, Xiaolin Xie, Zhigang Xue, Christophe Fliedel, Rinaldo Poli

\section{- To cite this version:}

Jirong Wang, Jianyu Han, Xiaolin Xie, Zhigang Xue, Christophe Fliedel, et al.. FeBr2-Catalyzed Bulk ATRP Promoted by Simple Inorganic Salts. Macromolecules, 2019, 52 (14), pp.5366-5376. 10.1021/acs.macromol.9b01015 . hal-02394069

\section{HAL Id: hal-02394069 \\ https://hal.science/hal-02394069}

Submitted on 30 Oct 2020

HAL is a multi-disciplinary open access archive for the deposit and dissemination of scientific research documents, whether they are published or not. The documents may come from teaching and research institutions in France or abroad, or from public or private research centers.
L'archive ouverte pluridisciplinaire HAL, est destinée au dépôt et à la diffusion de documents scientifiques de niveau recherche, publiés ou non, émanant des établissements d'enseignement et de recherche français ou étrangers, des laboratoires publics ou privés. 


\title{
FeBr2-Catalyzed Bulk ATRP Promoted by Simple Inorganic Salts
}

\author{
Jirong Wang, ${ }^{\dagger}$ Jianyu Han,${ }^{\dagger}$ Xiaolin Xie,${ }^{\dagger}$ Zhigang Xue ${ }^{\dagger, *}$ Christophe Fliedel ${ }^{\ddagger}$ and Rinaldo Poli ${ }^{\ddagger} *$ \\ $\dagger$ Key Laboratory for Material Chemistry of Energy Conversion and Storage, Ministry of Education, School of Chemistry \\ and Chemical Engineering, Huazhong University of Science and Technology, Wuhan 430074, P. R. China. ${ }^{\ddagger}$ CNRS, LCC \\ (Laboratoire de Chimie de Coordination), Université de Toulouse, UPS, INPT, 205 Route de Narbonne, BP 44099, F-31077 \\ Cedex 4, Toulouse, France.
}

KEYWORDS: ATRP, iron, inorganic salts, methyl methacrylate.

\begin{abstract}
The Atom Transfer Radical Polymerization of MMA in bulk at $70^{\circ} \mathrm{C}$, using ethyl 2-bromo-phenylacetate as initiator, is quite rapid and very well controlled when catalyzed by $\mathrm{FeBr}_{2}$ in the presence of small amounts of simple inorganic salts (chlorides, bromides, iodides, hydroxides, carbonates, bicarbonates, sulfates), comparing favorably in all respects, including technical simplicity, with the previously reported protocols that make use of salts of large organic cations or neutral organic ligands as promoters. A detailed investigation of the KBr-promoted process, supported by DFT calculations, suggests that the active form of the catalyst is a 1:1 adduct, which is stabilized in solution by weak MMA coordination to give an ion-paired $\mathrm{K}^{+}\left[\mathrm{Fe}^{\mathrm{II}} \mathrm{Br}_{3}\left(\mathrm{MMA}^{-}\right]^{-}\right.$species with a tetrahedral anion. The addition of 18 -crown-6 provides a less soluble but more active catalyst. $\mathrm{FeCl}_{2}$ performs less efficiently and the additions of small amounts of water to the system do not significantly affect the polymerization rate, whereas larger quantities result in rate reduction. The quality of the control is further improved when using 0.1 equivalents of the $\mathrm{FeBr}_{3}$ deactivator.
\end{abstract}

\section{Introduction}

Atom transfer radical polymerization (ATRP) is one of the most successful reversible deactivation radical polymerization (RDRP) methods to control the chain growth of more activated monomers such as acrylates, methacrylates and styrenics, yielding well-defined polymers with predictable molecular weights as well as narrow molecular weight distributions. ${ }^{1-9}$ Copper complexes, in combination with ligands that can tune the moderating equilibrium constant (Scheme 1) over more than 9 orders of magnitude, ${ }^{10-12}$ offer the widest flexibility. ${ }^{5,7}$, 13, 14 However, there is growing interest in using iron-based catalysts, ${ }^{15-21}$ in light of the greater availability and low cost of this metal, and especially because of its lower toxicity and higher biocompatibility. ${ }^{22-24}$

Scheme 1. General mechanism of ATRP initiation.

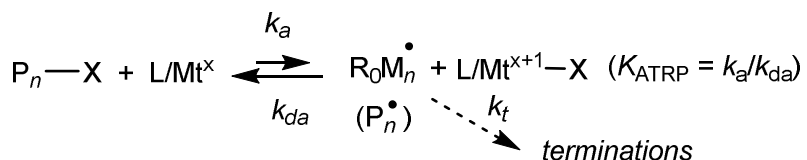

Numerous iron-based catalysts have been employed so far, generally based on $\mathrm{Fe}^{\mathrm{II}} \mathrm{X}_{2}(\mathrm{X}=$ halide $)$ stabilized by ligands such as phosphines, imines, amines, and various other neutral ligands including $N$-heterocyclic carbenes and carboxylic acids. ${ }^{15-21}$ Organic ligands can not only facilitate the dissolution of the iron salt in organic media but also tune the metal redox potential. These iron-based catalysts, generally carried out in polar solvents, are most successful for the ATRP of methacrylates. ${ }^{25}$ Previous work in our own group has focused on the ATRP of methyl methacrylate (MMA) in the presence of stabilizing ligands/solvents such as $\mathrm{PPh}_{3},{ }^{26}$ polar solvents (such as DMF, NMP, MeCN or $\left.\mathrm{PEG}_{200}\right)^{27-30}$ and in deep eutectic solvents. ${ }^{31}$

There are also a number of contributions on "organic ligand-free" Fe-based ATRP, where the ligand role is played by an inorganic anion (typically a halide) from a salt, in combination with either $\mathrm{FeX}_{2}$ and an alkyl halide initiator (direct activation) ${ }^{32-37}$ or with $\mathrm{FeX}_{3}$ and AIBN (reverse activation) ${ }^{32,38}$ or in other protocols (AGET, ${ }^{39-44}$ ARGET, ${ }^{45}$ ICAR, ${ }^{46}$ etc.). To the best of our knowledge, all these precedents made use of salts with large organic cations ("onium" salts such as tetrabutylammonium or -phosphonium, imidazolium, or tetrazonium). When such salts are low-melting (ionic liquids), they have also been used as solvents. ${ }^{40}$ It is also relevant to mention that, in a few cases, the beneficial role of additional additives, generally fully inorganic bases (i.e. with alkali or alkaline-earth metals) was highlighted. For instance, the rates of the styrene ${ }^{39}$ or $\mathrm{MMA}^{42}$ AGET ATRP using $\mathrm{FeCl}_{3}$, ascorbic acid as the reducing agent and tetrabutylammonium bromide ( $\mathrm{TBABr})$ or tetrabutylphosphonium bromide (TBPBr) as ligand were shown to be enhanced in the presence of catalytic amounts of inorganic bases $\left(\mathrm{NaOH}, \mathrm{Na}_{3} \mathrm{PO}_{4}, \mathrm{NaHCO}_{3}\right.$ and $\left.\mathrm{Na}_{2} \mathrm{CO}_{3}\right)$.

In a recent contribution, we have illustrated that simple inorganic salts $\left[\mathrm{Cat}^{+}\right]_{\mathrm{n}} \mathrm{X}^{\mathrm{n}-}\left(\mathrm{Cat}^{+}=\right.$alkali metal; $\mathrm{X}^{\mathrm{n}-}=$ chloride, bromide, iodide, carbonate, bicarbonate, sulfate, bisulfate, nitrate, hydroxide and hexafluorophosphate) are able, by themselves, to activate the typical ATRP initiator ethyl 2bromo-phenylacetate (EBrPA) to produce the $\mathrm{EPA}^{\circ}$ radical and a $\left[\mathrm{Cat}^{+}\right]_{\mathrm{n}}\left(\mathrm{XBr}^{*}\right)^{\mathrm{n}-}$ adduct, though this equilibrium does not provide a suitable persistent radical effect for a controlled polymerization of MMA. ${ }^{47}$ We now report that addition of $\mathrm{FeBr}_{2}$ to these systems affords a rapid MMA polymerization process, faster than the previously reported ones with more complex organic cations, yet with an equal or better level of 
control. To the best of our knowledge, an activating effect for $\mathrm{Fe}^{\mathrm{II}}$ ATRP catalysts by fully inorganic salt additives, in the absence of other organic molecules or salts, has not previously been reported. These new and simpler polymerization conditions constitute a significant advance in terms of the practical application of ATRP, because they combine the use of a readily available, inexpensive and non-toxic metal with equally available and inexpensive inorganic salts as ligands. The application of these polymerization conditions to other monomers will also be briefly shown. Finally, we will also present simple but apparently unprecedented considerations on $\mathrm{Fe}^{\mathrm{II}}$ coordination chemistry that establish the role of the $\left[\mathrm{FeBr}_{3}(\mathrm{MMA})\right]^{-}$complex as the active ATRP catalyst and help rationalize our results in comparison with those already available in the literature.

\section{Experimental section}

Materials. Methyl methacrylate (MMA, 98+\%, Sinpharm), Methyl acrylate (MA, 98+\%, Sinpharm), Butyl acrylate (BA, 98+\%, Sinpharm), Butyl methacrylate (BMA, 98+\%, Sinpharm) was passed through a column filled with neutral alumina, dried over calcium hydride $\left(\mathrm{CaH}_{2}\right)$, distilled under reduced pressure and stored in a freezer under argon. Ethyl $\alpha$ bromophenylacetate (EBrPA, 95\%, Alfa Aesar), ethyl $\alpha$ bromoisobutyrate (EBriB, 98\%, Alfa Aesar), methyl 2bromoisobutyrate (MBriB, 95+\%, Alfa Aesar), (1bromoethyl)benzene (PEBr, 97\%, Alfa Aesar), ethyl 2bromopropionate (EBrP, 98\%, Alfa Aesar), methyl 2bromopropionate (MBrP, 98\%, Alfa Aesar), 2bromopropionitrile (BPN, 98\%, Alfa Aesar), 2Chlomopropionitrile (CPN, 98\%, Alfa Aesar). iron(II) bromide $\left(\mathrm{FeBr}_{2}, 98+\%\right.$, Alfa Aesar), iron(II) chloride $\left(\mathrm{FeCl}_{2}\right.$, $98+\%$, Alfa Aesar), iron(II) chloride tetrahydrate $\left(\mathrm{FeCl}_{2}\right.$. $4 \mathrm{H}_{2} \mathrm{O}, 99.95 \%$, Macklin), 2,2,6,6-Tetramethylpiperidine 1-oxy (TEMPO, 98\%, Sigma Aldrich) were used without further purification. Sodium carbonate $\left(\mathrm{Na}_{2} \mathrm{CO}_{3}\right)$, sodium bicarbonate $\left(\mathrm{NaHCO}_{3}\right)$, potassium carbonate $\left(\mathrm{K}_{2} \mathrm{CO}_{3}\right)$, potassium bicarbonate $\left(\mathrm{KHCO}_{3}\right)$, potassium hydroxide $(\mathrm{KOH})$, sodium hydroxide $(\mathrm{NaOH})$, trisodium phosphate $\left(\mathrm{Na}_{3} \mathrm{PO}_{4}\right)$, disodium hydrogen phosphate $\left(\mathrm{Na}_{2} \mathrm{HPO}_{4}\right)$, sodium dihydrogen phosphate $\left(\mathrm{NaH}_{2} \mathrm{PO}_{4}\right)$, sodium sulfate $\left(\mathrm{Na}_{2} \mathrm{SO}_{4}\right)$, potassium sulfate $\left(\mathrm{K}_{2} \mathrm{SO}_{4}\right)$, rubidium sulfate $\left(\mathrm{Rb}_{2} \mathrm{SO}_{4}\right)$, cesium sulfate $\left(\mathrm{Cs}_{2} \mathrm{SO}_{4}\right)$, sodium nitrate $\left(\mathrm{NaNO}_{3}\right)$, potassium nitrate $\left(\mathrm{KNO}_{3}\right)$, sodium bisulphate $\left(\mathrm{NaHSO}_{4}\right)$, lithium chloride $(\mathrm{LiCl})$, sodium chloride $(\mathrm{NaCl})$, potassium chloride $(\mathrm{KCl})$, lithium bromide ( $\mathrm{LiBr})$, sodium bromide $(\mathrm{NaBr})$, potassium bromide $(\mathrm{KBr})$, rubidium bromide $(\mathrm{RuBr})$, cesium bromide $(\mathrm{CsBr})$, sodium iodide $(\mathrm{NaI})$, potassium iodide $(\mathrm{KI})$, tetra-n-butylammonium bromide ( $\mathrm{TBABr})$, magnesium chloride $\left(\mathrm{MgCl}_{2}\right)$, calcium chloride $\left(\mathrm{CaCl}_{2}\right)$, potassium hexaflurophosphate $\left(\mathrm{KPF}_{6}\right)$ and lithium trifluoromethylsulfonate (LiOTf), all from Sinpharm, were also used as received. Laboratory Reagent grade ( $\geqslant$ 99.5\%) N,N-dimethylformamide and toluene were purchased from VWR Chemicals and used after distillation.

Measurements. ${ }^{1} \mathrm{H}$ NMR spectroscopy was performed using Bruker AV400, AdvanceIII400 HD and Varian INOVA$400 \mathrm{MHz}$ spectrometers with deuterated chloroform as the solvent and tetramethylsilane (TMS) as the standard. The $\mathrm{M}_{\mathrm{n}}$ and $\mathrm{M}_{\mathrm{w}} / \mathrm{M}_{\mathrm{n}}$ of the polymers were determined by GPC using an Agilent 1100 gel permeation chromatograph equipped with a PLgel 79911GP-104 column $(7.5 \mathrm{~mm} \times 300 \mathrm{~mm}, 10 \mu \mathrm{m}$ bead size) or a Shimadzu system equipped with a Shimadzu RID-
20A refractive index detector and with two PSS SDV analytical columns (1000 $\AA$ and $100000 \AA, 5 \mu \mathrm{m}, 8 \times 300 \mathrm{~mm})$. THF was used as the eluent at a flow rate of $1 \mathrm{~mL} \mathrm{~min}^{-1}$ at $35^{\circ} \mathrm{C}$. Linear polystyrene standards were used for calibration.

General polymerization procedure. Unless otherwise stated, a typical system consisted of [monomer $]_{0} /\left[\mathrm{FeBr}_{2}\right]_{0} /$ [initiator $]_{0} /[\text { inorganic salts }]_{0}=200: 1: 1: 2$. A Schlenk flask $(25 \mathrm{~mL})$ was charged under argon with the salt and sealed by a rubber septum. Then the degassed monomer and initiator were added through degassed syringes. The solution was stirred for $20 \mathrm{~min}$ at room temperature. After three freeze-pump-thaw cycles, the flask was immersed in a thermostatic oil bath at the desired temperature. At timed intervals, samples were withdrawn from the flask with a degassed syringe. The monomer conversion was determined gravimetrically after the removal of the unconverted monomer under reduced pressure. The resulting residue was diluted with tetrahydrofuran (THF) and then filtered through a column filled with neutral aluminum oxide to remove any insoluble salt. The poly(methyl methacrylate) (PMMA) solution was then precipitated using an excess of $n$ hexane, and these polymers were dried under vacuum overnight at $80^{\circ} \mathrm{C}$ for gel permeation chromatography (GPC) characterization.

Solubility measurements. In a Schenk tube, neat MMA (3 $\mathrm{mL}, 2.82 \mathrm{~g}, 28.17 \mathrm{mmol})$ and the desired compound(s) (KBr, $\mathrm{FeBr}_{2}, \mathrm{LiBr}_{\mathrm{FeBr}}$ 1:1, $\mathrm{KBr}: \mathrm{FeBr}_{2}$ 1:1, or $\mathrm{KBr}: 16$-crown6: $\mathrm{FeBr}_{2}$ 1:1:1) were introduce with an MMA/Fe molar ratio of 200:1 (for instance, the amount of $\mathrm{FeBr}_{3}$ was $30 \mathrm{mg}(0.139$ $\mathrm{mmol}$ ). The mixture was then stirred at $70^{\circ} \mathrm{C}$ for several hours, in order to reach thermal equilibrium for the solid dissolution process. It was then filtered hot through a filter-cannula into a new and pre-weighed Schlenk tube and the solution was then evaporated to dryness. The residue amount was obtained by weight difference.

Computational details. The computational work was carried out using the Gaussian09 suite of programs. ${ }^{48}$ Gas-phase geometry optimizations were performed without any symmetry constraint using the BPW91* functional, which is a reparametrized version of B3PW91 with the same parameters previously optimized for B3LYP. ${ }^{49}$ This functional was shown to provide an accurate description of open-shell transition metal complexes, particularly those of $\mathrm{Fe}^{\mathrm{II}} .{ }^{50}$ Dispersion effects were taken into account with Grimme's D3 empirical method during optimization (BPW91*-D3), using SR6 and S8 parameters identical to those optimized for B3PW91. ${ }^{51}$ The 6$31 \mathrm{G}(\mathrm{d}, \mathrm{p})$ basis functions were used for all light atoms $(\mathrm{H}, \mathrm{C}$, $\mathrm{O})$. The $\mathrm{Br}$ atom was treated at three different levels. The lowest one is via same 6-31G(d,p) basis set as the light atoms. However, since a better description of anionic complexes with outer halogen atoms requires the addition of diffuse functions, a second level used the augmented basis set $6-31+G(d, p)$ for this atom. In a third level, the $\mathrm{Br}$ atom was described by the LANL208d basis, ${ }^{52}$ which contains an ECP and a triple-zeta valence shell plus a $d$ polarization function $(\alpha=0.434)$ and a diffused $p$ function $(\alpha=0.0376)$. The Fe atom was treated with the SDD basis set augmented by an $\mathrm{f}$ polarization function $(\alpha$ $=2.462)^{53}$ in combination with the $6-31 \mathrm{G}(\mathrm{d}, \mathrm{p})$ or $6-31+\mathrm{G}(\mathrm{d}, \mathrm{p})$ functions for $\mathrm{Br}$, or with the LANL08(f) basis ${ }^{54}$ in combination with the LANL208d basis for Br. The unrestricted formulation was used for the open-shell $\mathrm{Fe}^{\mathrm{II}}$ complexes, yielding only minor spin contamination $\left(\left\langle\mathrm{S}^{2}\right\rangle\right.$ at convergence was very close to the expected value of 6.0 for all quintet states, the 
maximum deviation being 6.013 for $\left[\mathrm{FeBr}_{2}(\mathrm{MMA})_{2}\right]$ with the LANL basis functions). The dinuclear $\left[\mathrm{Fe}_{2} \mathrm{Br}_{6}\right]^{2-}$ was treated as the spin aligned $S=9$ state $\left(\left\langle S^{2}\right\rangle\right.$ was in all cases 20.015 vs. the expected value of 20). All final geometries were characterized as local minima by verifying that all second derivatives of the energy were positive. Thermochemical corrections were obtained at $298.15 \mathrm{~K}$ on the basis of frequency calculations, using the standard approximations (ideal gas, rigid rotor and harmonic oscillator). Solvation effects in neat MMA were taken into account by treating the solvent medium as a polarizable continuum with the SMD approach, ${ }^{55}$ using $\varepsilon=6.534$ as the dielectric constant. A further correction of $1.95 \mathrm{Kcal} \mathrm{mol}^{-1}$ was applied to bring the $G$ values from the gas phase (1 atm) to the solution $\left(1 \mathrm{~mol} \mathrm{~L}^{-1}\right)$ standard state. ${ }^{56}$

\section{Results and discussion}

\section{Polymerizations with a bromide salt additive}

We have recently shown that the MMA polymerization initiated by ethyl 2-bromo-phenylacetate (EBrPA) experiences an activating effect by a variety of inorganic salts. ${ }^{47}$ The effect of the alkali metal bromides is reminded in Table 1 (compare entries 2-6 with entry 1). For instance, use of $\mathrm{KBr}$ gave $8.1 \%$ conversion after $18 \mathrm{~h}$ at $90^{\circ} \mathrm{C}$ (entry 4$){ }^{47}$ This activating effect was shown to involve atom transfer to yield the $\mathrm{EPA}^{\circ}$ radical and $\mathrm{M}^{+}\left(\mathrm{Br}_{2}{ }^{*}\right)^{-}$deactivator $(\mathrm{Mt}=$ alkali metal), which is however incapable of providing a good enough persistent radical effect for a controlled chain growth. The more soluble TBABr yielded faster conversion (entry 7) but was equally incapable of controlling the polymerization. We now report that the addition of $\mathrm{FeBr}_{2}$ to these systems leads to a quite rapid and well-controlled chain growth, even at a lower temperature $\left(70^{\circ} \mathrm{C}\right)$, with $M_{\mathrm{n}}$ close to target and low $\oslash$ for all metal systems, see entries 9-14. The polymerization rate is highly metal-dependent, with much slower conversions for the bromides of the heavier metals $\mathrm{Rb}$ and $\mathrm{Cs}$ (less than $20 \%$ conversion after $20 \mathrm{~h}$, entries 12 and 13 , whereas a $74.1 \%$ conversion was obtained in the presence of $\mathrm{LiBr}$ in $1 \mathrm{~h}$ (entry 9). Under these conditions, no monomer conversion was observed in the absence of bromide salt additive (entry 8 ). The effect of these alkali metal bromides on the $\mathrm{FeBr}_{2} / \mathrm{EBrPA}$ action in bulk MMA polymerization is similar to that previously reported for several other bromide salts with large organic cations (tetraalkylammonium or -phosphonium, 32, 36, 41, 42, 44, 45 substituted imidazoliums ${ }^{33}$ and phosphazenium ${ }^{35}$ ). The lighter alkali metal bromides ( $\mathrm{Li}, \mathrm{Na}, \mathrm{K})$, however, yield much faster polymerizations than the more soluble $\mathrm{TBABr}$ additive under the same operating conditions (entry 14).

The polymerizations carried out in the presence of $\mathrm{LiBr}$, $\mathrm{NaBr}, \mathrm{KBr}$ and $\mathrm{TBABr}$ were investigated in greater details, see Figure 1 (the raw data are available in Table S1; for all polymerization kinetics reported in this contribution, the $k_{\mathrm{obs}}$ values obtained from the fit of the $1^{\text {st }}$ order plots are reported together with the raw data in the Supporting Information). All polymerizations are well-controlled, with linear first-order plots, linear $M_{\mathrm{n}}$ grown with conversion in close agreement with the theoretical molar masses, and low $Ð$ values $(\leq 1.25)$. The $k_{\text {obs }}$ values increase in the order TBA $\left(8.7 \cdot 10^{-3}\right)<\mathrm{K}$ $\left(1.16 \cdot 10^{-2}\right) \sim \mathrm{Na}\left(1.15 \cdot 10^{-2}\right)<\mathrm{Li}\left(2.17 \cdot 10^{-2}\right)$, all values being in $\min ^{-1}$. Although these polymerizations appear quite wellcontrolled, the presence of a significant degree of initial terminations is nevertheless suggested by the positive intercepts of the first-order kinetic plots. These terminations probably produce short chains that are lost during the polymer work-up for the GPC analysis, thus the observed $M_{n}$ values agree rather well with the theoretical ones. An improvement was achieved through addition of $\mathrm{FeBr}_{3}$ (vide infra).

The system with $\mathrm{KBr}$ as additive was selected for additional investigations. The radical nature of the polymerization process was proven by a polymerization run under the same conditions as in entry 11, but with addition of TEMPO $45 \mathrm{~min}$ after starting the reaction, when the conversion was $38.7 \%$. Continued heating at $70^{\circ} \mathrm{C}$ for $2 \mathrm{~h}$ did not further increase the conversion (see SI, Figure S1 and Table S2). In addition, the ${ }^{1} \mathrm{H}$ NMR analysis of the recovered polymers from the experiments run in the presence of $\mathrm{LiBr}, \mathrm{NaBr}$ and $\mathrm{KBr}$ showed identical mm:mr:rr ratios, within the integration error, to a PMMA obtained by free radical polymerization initiated by AIBN, see Figure S2. This result not only confirms the radical nature of the process, it also shows a negligible influence of the salt additive on the chain propagation stereochemical control. A chain extension experiment, carried out with the PMMA-Br product of entry 1 (Table 1 ) as macroinitiator, gave rise to a chain length increase in line with the expected target values, maintaining a monomodal distribution and a low dispersity (Table S3 and Figure S3). Polymerizations run in the presence of $\mathrm{KBr}$ and with dilution by a polar (DMF) or a nonpolar (toluene) solvent (MMA:solvent $(\mathrm{v} / \mathrm{v})=2: 1)$ provide in both cases similar control but slower rates, as expected (Table S4 and Figure S4). At the polymerization temperature, the $\mathrm{KBr}$ salt is more soluble in the presence of DMF and less soluble in the presence of toluene, relative to the bulk monomer conditions.
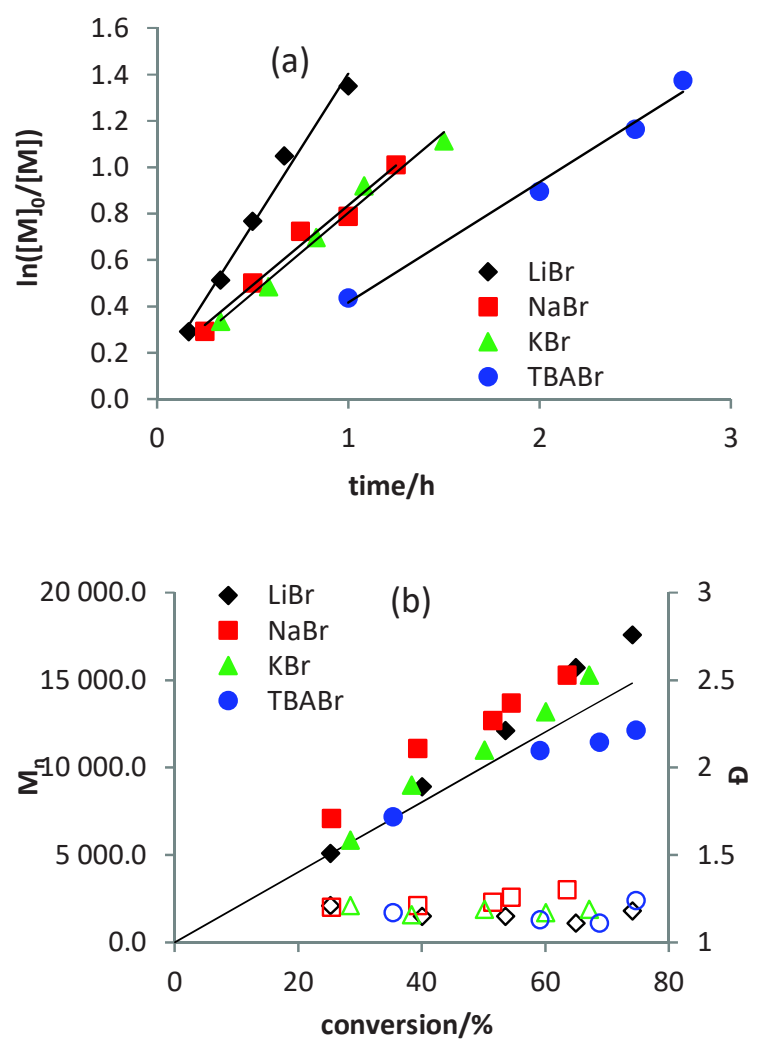

Figure 1. First-order plots (a) and evolution of $M_{\mathrm{n}}$ and $Ð$ with conversion (b) for the bulk $\mathrm{FeBr}_{2}$-catalyzed and EBrPA-initiated MMA polymerization in the presence of different bromide salts. $[\mathrm{MMA}]:\left[\mathrm{FeBr}_{2}\right]:[\mathrm{EBrPA}]:[\mathrm{salt}]=200: 1: 1: 2, \mathrm{~T}=70^{\circ} \mathrm{C}$. 
Table 1. FeBr2-cataltyzed MMA ATRP: effect of inorganic bromide salts. ${ }^{a}$

\begin{tabular}{|c|c|c|c|c|c|c|c|c|c|c|}
\hline & Initiator & Catalyst & Additive & $\mathrm{T} /{ }^{\circ} \mathrm{C}$ & Time/h & Conv. $/ \%$ & $\mathrm{Mn}, \mathrm{th} / \mathrm{g} \mathrm{mol}^{-1}$ & $\mathrm{Mn}, \mathrm{GPC} / \mathrm{g} \mathrm{mol}^{-1}$ & $Đ$ & Ref. \\
\hline 1 & EBrPA & none & none & 90 & 12.0 & 2.3 & 700 & 11400 & 1.37 & 47 \\
\hline 2 & EBrPA & none & $\mathrm{LiBr}$ & 90 & 12.0 & 9.6 & 2200 & 26600 & 1.34 & 47 \\
\hline 3 & EBrPA & none & $\mathrm{NaBr}$ & 90 & 12.0 & 13.0 & 2800 & 62600 & 1.71 & 47 \\
\hline 4 & EBrPA & none & $\mathrm{KBr}$ & 90 & 18.0 & 8.1 & 1900 & 146800 & 2.16 & 47 \\
\hline 5 & EBrPA & none & $\mathrm{RbBr}$ & 90 & 12.0 & 5.1 & 1300 & 20400 & 1.68 & 47 \\
\hline 6 & EBrPA & none & $\mathrm{CsBr}$ & 90 & 12.0 & 4.8 & 1200 & 17800 & 1.76 & 47 \\
\hline 7 & EBrPA & none & $\mathrm{TBABr}$ & 90 & 18.0 & 36.7 & 7600 & 655400 & 2.49 & 47 \\
\hline 8 & EBrPA & $\mathrm{FeBr}_{2}$ & none & 70 & 15.0 & 0.0 & - & - & - & This work \\
\hline 9 & EBrPA & $\mathrm{FeBr}_{2}$ & $\mathrm{LiBr}$ & 70 & 1.0 & 74.1 & 15100 & 17600 & 1.18 & This work \\
\hline 10 & EBrPA & $\mathrm{FeBr}_{2}$ & $\mathrm{NaBr}$ & 70 & 2.0 & 65.6 & 13400 & 15300 & 1.30 & This work \\
\hline 11 & EBrPA & $\mathrm{FeBr}_{2}$ & $\mathrm{KBr}$ & 70 & 1.5 & 67.2 & 13700 & 15200 & 1.19 & This work \\
\hline 12 & EBrPA & $\mathrm{FeBr}_{2}$ & $\mathrm{RbBr}$ & 70 & 12.0 & 19.9 & 4000 & 4600 & 1.17 & This work \\
\hline 13 & EBrPA & $\mathrm{FeBr}_{2}$ & $\mathrm{CsBr}$ & 70 & 12.0 & 6.3 & 1500 & 1700 & 1.15 & This work \\
\hline 14 & EBrPA & $\mathrm{FeBr}_{2}$ & $\mathrm{TBABr}$ & 70 & 2.75 & 74.7 & 15000 & 12100 & 1.24 & This work \\
\hline
\end{tabular}
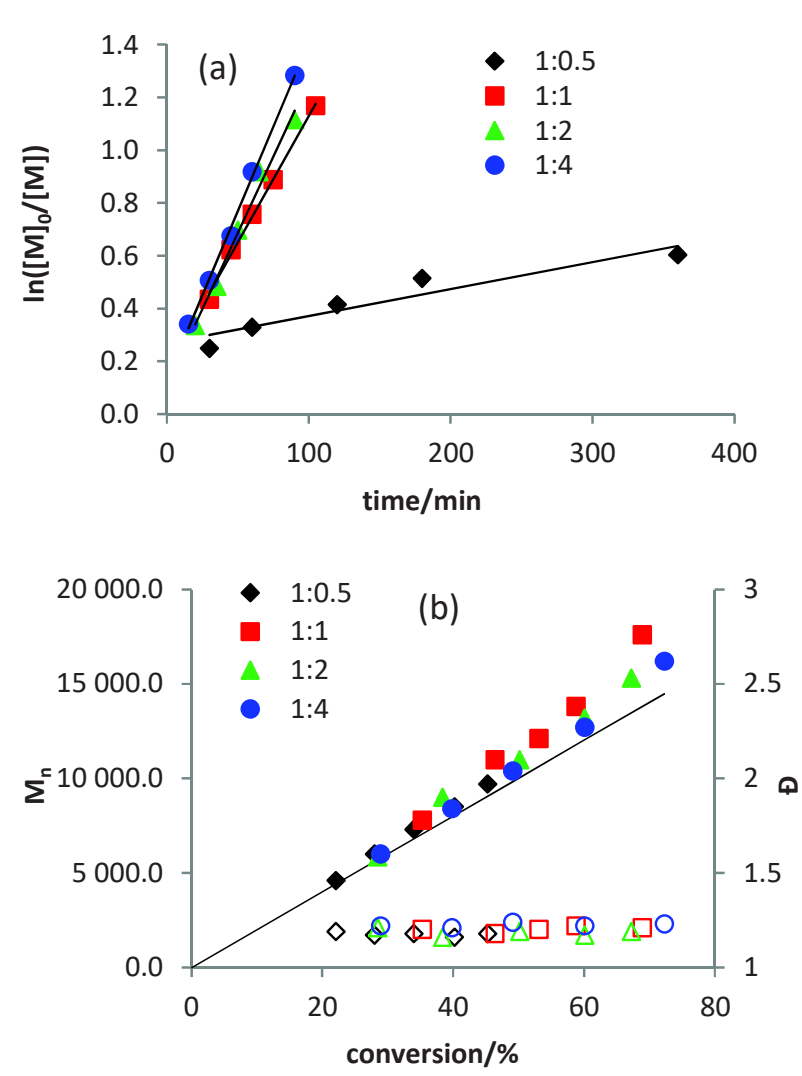

Figure 2. First-order plots (a) and evolution of $M_{\mathrm{n}}$ and $Ð$ with conversion (b) for the EBrPA-initiated bulk MMA polymerizations with $\mathrm{FeBr}_{2}$ activation and different $\mathrm{Fe}^{\mathrm{II}} / \mathrm{KBr}$ ratios.

The effect of the $\mathrm{Fe}^{\mathrm{II}} / \mathrm{KBr}$ ratio is shown in Table $\mathrm{S} 5$ and Figure 2. Using only 0.5 equivalents of $\mathrm{KBr}$ relative to $\mathrm{FeBr}_{2}$ resulted in a much slower rate $\left(k_{\mathrm{obs}}=1.03 \cdot 10^{-3} \mathrm{~min}^{-1}\right)$ than with the stoichiometric amount $\left(k_{\text {obs }}=9.6 \cdot 10^{-3} \mathrm{~min}^{-1}\right)$ while the polymerization was still quite well-controlled. A further increase beyond the stoichiometric amount ( 2 and 4 equivalents) did not have a large effect $\left(k_{\mathrm{obs}}=1.2 \cdot 10^{-2}\right.$ and $1.3 \cdot 10^{-2} \mathrm{~min}^{-1}$, respectively), suggesting that the active species has a 1:1 $\mathrm{FeBr}_{2} / \mathrm{KBr}$ ratio. More specifically, as it will be discussed in the next section, the nature of the active catalyst appears to correspond to the tetrahedral monoanionic $\left[\mathrm{Fe}^{\mathrm{II}} \mathrm{Br}_{3}(\mathrm{MMA})\right]^{-}$ complex.

Further polymerizations carried out with a variable monomer/Fe $/ \mathrm{II}^{\mathrm{II}}$ ratio yielded polymers with target $M_{\mathrm{n}}$ values, scaling with the MMA/Fe ratio, always with $D<1.25$ (Table S6 and Figure S5a). Interestingly, the polymerization rates also scale approximately with $\left[\mathrm{FeBr}_{2}\right]$ (see Figure 3), which suggests that the catalyst is mostly or fully dissolved in the polymerization medium. Indeed, a solubility test shows that whereas $\mathrm{FeBr}_{2}$ and $\mathrm{KBr}$ are only little soluble in neat MMA (saturated solutions at $70^{\circ} \mathrm{C}$ have respectively $\left[\mathrm{FeBr}_{2}\right]=0.012 \mathrm{~mol} \mathrm{~L}^{-1}$ and $\left.[\mathrm{KBr}]=0.0098 \mathrm{~mol} \mathrm{~L}^{-1}\right)$, the solubility increases substantially upon addition of $\mathrm{KBr}$ ( 1 equiv) to yield $\left[\mathrm{KFeBr}_{3}\right]=0.026 \mathrm{~mol}$ $\mathrm{L}^{-1}$ for a saturated solution at $70^{\circ} \mathrm{C}$. At the highest $\mathrm{Fe}^{\mathrm{II}} / \mathrm{MMA}$ ratio (1:200, corresponding to a theoretical amount of 0.047 mol $\left.\mathrm{L}^{-1}\right)$, the mixture is supersaturated and indeed undissolved catalyst is initially observed in the polymerization mixture. However, homogeneous solutions were observed for the polymerizations carried out with 1:400, 1:600 and 1:800 ratios (corresponding to $0.0235,0.0176$ and $0.0117 \mathrm{~mol} \mathrm{~L}^{-1}$, respectively, i.e. lower than the experimentally measured concentration at saturation). 


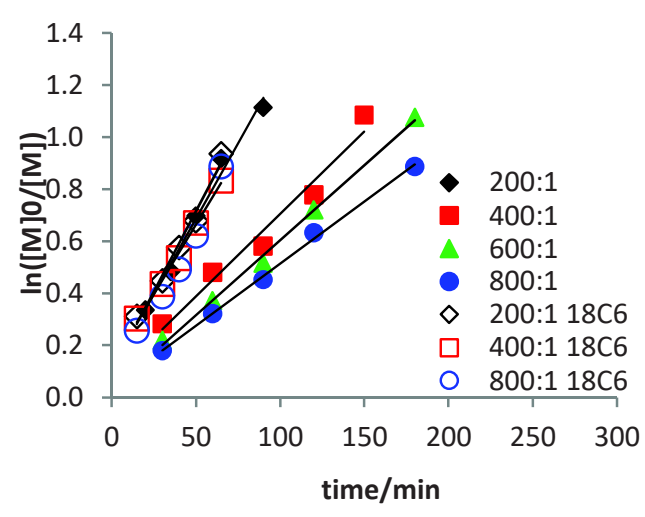

Figure 3. First-order plots the bulk $\mathrm{FeBr}_{2}-\mathrm{KBr}$-catalyzed and EBrPA-initiated MMA polymerization at $70^{\circ} \mathrm{C}$ with variable [MMA]:[ $\left.\mathrm{FeBr}_{2}\right]$ ratios and in the absence or presence of $18-$ crown-6 (18C6). Conditions: [MMA]:[FeBr2]:[EBrPA]:[KBr]:[18C6] = x:1:1:2:y $(\mathrm{x}=200,400$, $600,800 ; y=0$ or 1$)$.

Additional polymerizations were also carried out under the same conditions, except for the presence of one equiv of 18crown-6 (18C6) per $\mathrm{KBr}$, which is known to strongly bind the $\mathrm{K}^{+}$ion (Table S6). This complexing agent is also known to render potassium salts more lipophilic, generally increasing their solubility in organic solvents. However, unexpectedly, the resulting $\mathrm{K}(18 \mathrm{C} 6) \mathrm{FeBr}_{3}$ turned out to be less soluble than $\mathrm{KFeBr}_{3}$, as qualitatively indicated by the greater amount of undissolved catalyst and by the fainter color of the decanted solution. The concentration at saturation in neat MMA at $70^{\circ} \mathrm{C}$ was measured as $0.017 \mathrm{~mol} \mathrm{~L}^{-1}$, i.e. ca. half the saturation concentration of $\mathrm{KFeBr}_{3}$. The polymerizations run with this catalyst gave again a good first-order kinetic behavior, but the observed rate constants in this case were essentially independent on the MMA/Fe ratio (Figure 3). This is consistent with the fact that all polymerization mixtures are saturated in catalyst, even at the highest dilution $\left(\mathrm{MMA} / \mathrm{Fe}^{\mathrm{II}}=800: 1\right)$. A further point of interest is that the observed rate constants for the $\mathrm{K}(18 \mathrm{C} 6) \mathrm{FeBr}_{3}$-catalyzed polymerization are greater than for the $\mathrm{KFeBr}_{3}$-catalyzed polymerizations run at the same $\mathrm{MMA} / \mathrm{Fe}$ ratio, even though the catalyst concentration is lower and reaching approximately equal $k_{\mathrm{obs}}$ values only at the highest dilution. This reveals a critical role of the cation in the regulation of the ATRP equilibrium (see further discussion below). The ATRP catalyzed by the $\mathrm{K}(18 \mathrm{C} 6) \mathrm{FeBr}_{3}$ system is not only faster, but also better-controlled, than that catalyzed by $\mathrm{KFeBr}_{3}$, with $Đ$ values down to 1.03 (Figure S5b).

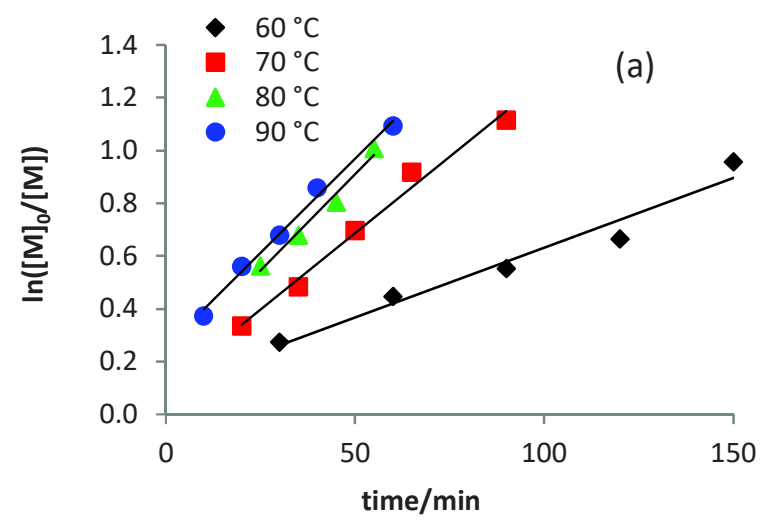

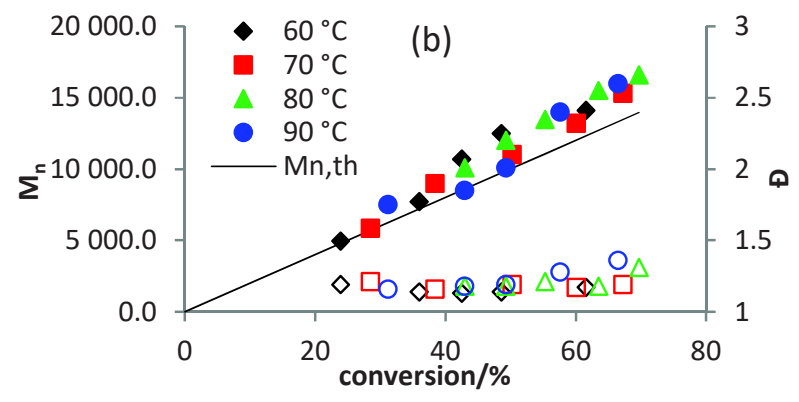

Figure 4. First-order plots (a) and evolution of $M_{\mathrm{n}}$ and $Ð$ with conversion (b) for the bulk $\mathrm{FeBr}_{2}-\mathrm{KBr}$-catalyzed and EBrPAinitiated MMA polymerization at different temperatures. [MMA]:[FeBr2]:[EBrPA]:[KBr] = 200:1:1:2.

Exploration of the temperature effect for the polymerization run with a MMA/Fe ratio of 200 showed a significant rate decrease when lowering $\mathrm{T}$ from 70 to $60^{\circ} \mathrm{C}$, whereas the rate did not significantly increase at higher temperatures, see Table S7 and Figure 4. This phenomenon can be attributed to the higher impact, at higher temperatures, of terminations in the initial phase of the process, resulting in a significant decrease of the chain carriers. This is also indicated by the greater positive intercept of the first-order plot in Figure 4a. On the other hand, the level of control remained quite acceptable under all conditions, with $M_{\mathrm{n}}$ values quite close to target and $D<1.3$. Thus, $70^{\circ} \mathrm{C}$ appears as the most suitable polymerization temperature and was maintained for the additional studies.

A screening of the polymerization using different initiators showed slow initiation for several of them (e.g. CPN, MBrP, $\mathrm{EBrP}, \mathrm{PEBr}$ ), as evidenced by the presence of an induction time (negative intercept in the first-order kinetic plot) and/or by lower $k_{\mathrm{obs}}$ in the kinetics plot (see Table S8 and Figure S6), as well as by greater molar masses than the target values in the $M_{\mathrm{n}}$ vs. conversion plot. On the other hand, EBrPA, EBiB and $\mathrm{MBiB}$ gave the highest and reasonably similar polymerization rates, with $M_{\mathrm{n}}$ values close to target. These results are in line with the common knowledge that only the fastest initiators, which yield more stabilized radicals and are associated with a greater $K_{\mathrm{ATRP}}$ (Scheme 1), are suitable for the polymerization of MMA. ${ }^{57-59}$ The investigations were therefore continued with EBrPA as initiator.

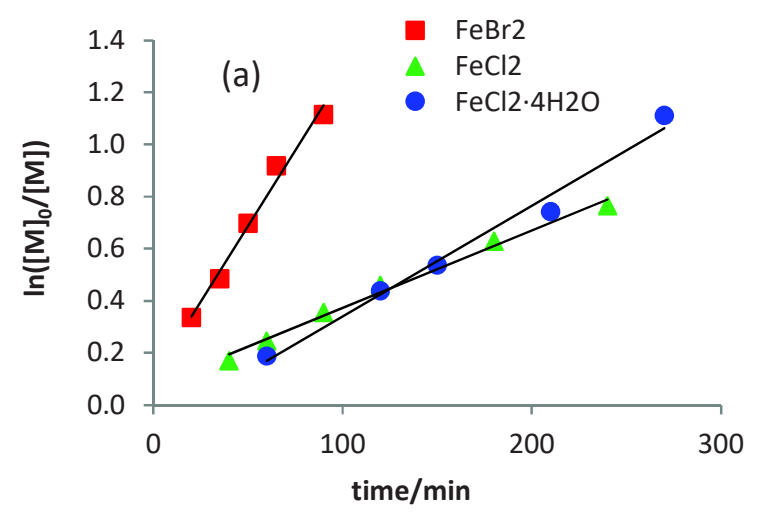




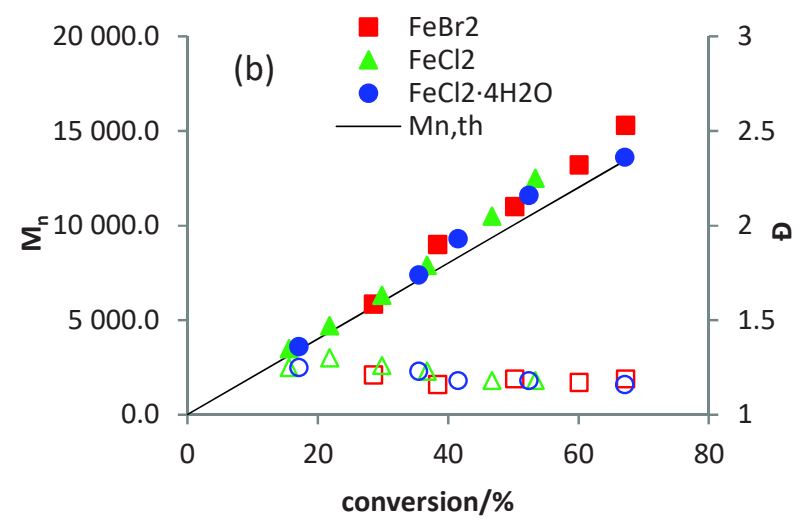

Figure 5. First-order plots (a) and evolution of $M_{\mathrm{n}}$ and $Ð$ with conversion (b) for the EBrPA-initiated bulk MMA polymerizations ([MMA]:[MtX $]:[\mathrm{EBrPA}]:[\mathrm{KBr}]=200: 1: 1: 2$ ) using different metal catalysts at $70^{\circ} \mathrm{C}\left(\mathrm{MtX}_{2}=\mathrm{FeBr}_{2}, \mathrm{FeCl}_{2}, \mathrm{FeCl}_{2} \cdot 4 \mathrm{H}_{2} \mathrm{O}\right)$.

A brief investigation of different $\mathrm{Fe}^{\mathrm{II}}$ catalysts for the standard EBrPA-initiated bulk polymerization in the presence of 2 equivalents of $\mathrm{KBr}$ has given the results shown in Table S9 and Figure 5. The polymerization is much faster with $\mathrm{FeBr}_{2}$ than with $\mathrm{FeCl}_{2}$. Use of the hydrated form of the chloride salt, $\mathrm{FeCl}_{2} \cdot 4 \mathrm{H}_{2} \mathrm{O}$, did not significantly affect the polymerization rate, but shows a small induction time (negative intercept of the first-order kinetic plot), possibly related to the need to replace the coordinated water molecules in order to obtain the catalytically active species. All polymerizations are equally well-controlled (Figure 5b). A comparison of rates between the $\mathrm{FeCl}_{2}$ - and $\mathrm{FeBr}_{2}$-catalyzed ATRP of MMA was also previously made in the presence of the phosphazene halides $\left.\left[\left\{\left(\mathrm{Me}_{2} \mathrm{~N}\right)_{2} \mathrm{P}=\mathrm{N}\right\} \mathrm{y}_{4}\right\} \mathrm{P}\right]^{+} \mathrm{X}^{-}(\mathrm{X}=\mathrm{Cl}, \mathrm{Br}),{ }^{35}$ although based only on a single point measurement rather than on kinetics studies. All $\mathrm{FeX}_{2} / \mathrm{Y}^{-}$combinations $(\mathrm{X}, \mathrm{Y}=\mathrm{Cl}, \mathrm{Br})$ gave rather similar and much slower rates (ca. $75-90 \%$ conversions in $72 \mathrm{~h}$ at $60^{\circ} \mathrm{C}$ ) relative to those of Figure 5. The greater dependence on the nature of the iron salt in our study may be related to the lower solubility of $\mathrm{K}^{+}\left[\mathrm{Fe}^{\mathrm{II}} \mathrm{Cl}_{2} \mathrm{Br}(\mathrm{MMA})\right]^{-}$relative to $\mathrm{K}^{+}\left[\mathrm{Fe}^{\mathrm{II}} \mathrm{Br}_{3} \text { (MMA) }\right]^{-}$, while the two salts may have comparable solubility when associated to the large phosphazene cation. The rest of the study was therefore limited to $\mathrm{FeBr}_{2}$ as catalyst.

A significant improvement of the polymerization control, while retaining a quite rapid monomer conversion, could be achieved by introduction of a small amount of $\mathrm{FeBr}_{3}$ deactivator ( 0.1 equivalents relative to the $\mathrm{FeBr}_{2}$ activator). The results for the three lighter alkali metal salts are provided in Table S10 and Figure 6 . The improved quality can immediately be assessed by the lower dispersity values, which decrease to < 1.1 at high conversions. A reduced degree of initial terminations, as expected when working in the presence of deactivator, is indicated by the close-to-zero intercepts. A more detailed comparison of the polymerization kinetics for each bromide salt is shown in the SI (Figure S7).
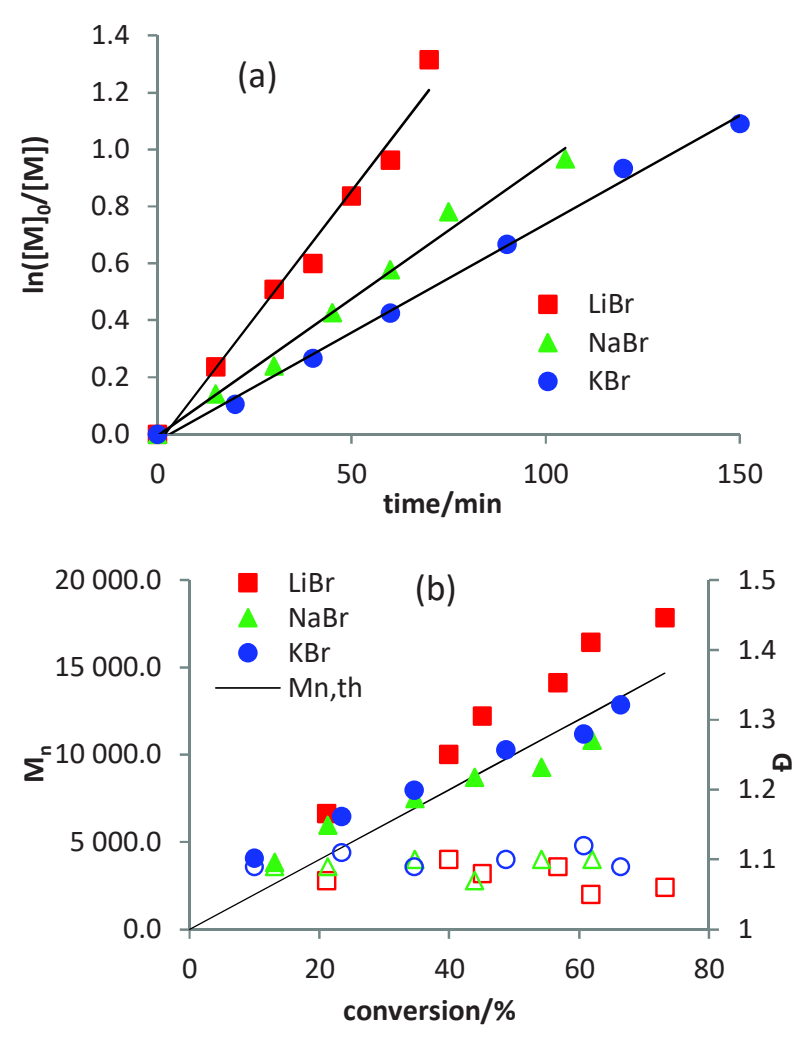

Figure 6. First-order plots (a) and evolution of $M_{\mathrm{n}}$ and $Ð$ with conversion (b) for the EBrPA-initiated bulk MMA polymerizations with $\mathrm{FeBr}_{2}-\mathrm{MtBr}$ activation $(\mathrm{Mt}=\mathrm{Li}, \mathrm{Na}, \mathrm{K})$ in the presence of $\mathrm{FeBr}_{3}$ ([MMA]:[$\left[\mathrm{FeBr}_{2}\right]:\left[\mathrm{FeBr}_{3}\right]:[\mathrm{EBrPA}]:[\mathrm{MtBr}]=$ 200:1:0.1:1:2) at $70^{\circ} \mathrm{C}$.

In each case, the first order plot obtained in the presence of $\mathrm{FeBr}_{3}$ shows an equally good or better linear correlation and an intercept much closer to zero, relative to the corresponding plot obtained in the absence of $\mathrm{FeBr}_{3}$. The $k_{\mathrm{obs}}$ values are not greatly reduced by the $\mathrm{FeBr}_{3}$ presence because of the lower impact of initial terminations. Indeed, a significant amount of $\mathrm{FeBr}_{3}$ is also generated by terminations in the polymerizations run without the initial addition of this reagent. For instance, the faster $\mathrm{LiBr}$ system gives a $k_{\mathrm{obs}}$ value of $2.17 \cdot 10^{-2} \mathrm{~min}^{-1}$ in the absence of initial $\mathrm{Fe}^{\mathrm{III}}$ and $1.78 \cdot 10^{-2} \mathrm{~min}^{-1}$ in the presence of $\mathrm{Fe}^{\mathrm{III}}$. Finally, the $\mathrm{KBr}$ system was also tested in the presence of deliberately added water. In the presence of only 2 equivalents per $\mathrm{FeBr}_{2}$, a slight induction time is observed as indicated by the negative intercept of the $1^{\text {st }}$ order plot and the rate slightly increased $\left(8.6 \cdot 10^{3} \mathrm{~min}^{-1}\right.$, vs. $7.6 \cdot 10^{3} \mathrm{~min}^{-1}$, see Table S10 and Figure S8), although these effects are very small. Note that the same phenomenon was also pointed out above when comparing the kinetics of the polymerization catalyzed by $\mathrm{FeCl}_{2}$ and $\mathrm{FeCl}_{2} \cdot 4 \mathrm{H}_{2} \mathrm{O}$. This result allows us to conclude that different rates observed for the salts with different cations do not originate from random differences in the hydration of the various additives, which had been nonetheless obtained commercially as anhydrous materials and stored in the dry box. When using, however, a much larger excess of water (60 equivalents per $\mathrm{FeBr}_{2}$ ), the polymerization became much slower (Table S10 and Figure S8), as a consequence of the decreased catalyst solubility as evidenced by the formation of an oily deposit. A similar rate decrease upon addition of 
water was also observed for the EBrPA-initiated ATRP of MMA in anisole. ${ }^{45}$

2. Nature of the catalytically active species for the $\mathrm{FeBr}_{2} / \mathrm{Br}^{-}$system.

Dissolution of $\mathrm{FeBr}_{2}$ in non-ionizing donor solvents is likely to generate neutral 4-coordinate $\mathrm{Fe}^{\mathrm{II}} \mathrm{Br}_{2} \mathrm{~L}_{2}$ complexes ( $\mathrm{L}=$ solvent molecule), as suggested by the $\mathrm{X}$-ray structures of several $\mathrm{Fe}^{\mathrm{II}} \mathrm{X}_{2} \mathrm{~L}_{2}$ complexes $(\mathrm{X}=\mathrm{Cl}, \mathrm{Br}, \mathrm{I}),{ }^{60-64}$ including two unpublished structures (DIZXUH and NENWEK) in the Cambridge Crystallographic Structural Database (CCSD), whereas ionizing solvents that generate cationic complexes give rise to 5- or 6-coordinated complexes. For the bulk polymerization of MMA, the monomer itself is likely to assume the ligand role via the more donating carbonyl $\mathrm{O}$ lone pair, therefore generating the tetrahedral complex $\mathrm{FeBr}_{2}(\mathrm{MMA})_{2}$. The bromide anion is known to add to $\mathrm{FeBr}_{2}$ to yield tetrahedral $\left[\mathrm{Fe}^{\mathrm{II}} \mathrm{Br}_{4}\right]^{2-}$ when used in large excess in a polar solvent, ${ }^{65}$ whereas use of a stoichiometric amount yields a monoanionic tetrahedral $\left[\mathrm{FeBr}_{3} \mathrm{~L}\right]^{-}$adduct in the presence of neutral donors L. Complexes of this kind have been isolated and fully characterized, in combination with various cations, for $\mathrm{L}=\mathrm{THF}^{66,67} \mathrm{~N}$ heterocyclic carbenes, ${ }^{66}$ or tertiary phosphine $\left(\mathrm{PR}_{3}\right) .{ }^{68,69}$ In the absence of sufficiently donating ligands, the dinuclear dibromo-bridged complex $\left[\mathrm{Fe}_{2} \mathrm{Br}_{6}\right]^{2-}$ ion may also be generated. The latter is yet unreported in discrete molecular systems, but was observed in the crystal structure of $\mathrm{KFeBr}_{3}{ }^{70}$ Therefore, the controlling equilibrium in bulk MMA probably involves the tetrahedral $\left[\mathrm{FeBr}_{3}(\mathrm{MMA})\right]^{-}$catalyst as activating species and the known ${ }^{65}$ tetrabromoferrate(III) ion, $\left[\mathrm{Fe}^{\mathrm{III}} \mathrm{Br}_{4}\right]^{-}$as deactivator (It is of interest to compare our experimental results for the polymerization rate as a function of $\mathrm{Br}^{-} / \mathrm{FeBr}_{2}$ ratio with those reported in the literature. For our $\mathrm{FeBr}_{2} / \mathrm{KBr}$ system, the amount of bromide salt does not affect the rate when added in greater amounts than 1 equivalent per $\mathrm{FeBr}_{2}$ (Figure 2). On the other hand, Matyjaszewski et al. ${ }^{32}$ have shown that the rate of the $\mathrm{FeBr}_{2} /\left[n \mathrm{Bu}_{4} \mathrm{E}\right] \mathrm{Br}$-catalyzed $(\mathrm{E}=\mathrm{N}, \mathrm{P}) \mathrm{MMA}$ polymerization (as well as those of styrene and MA) decreases upon increasing the salt $/ \mathrm{FeBr}_{2}$ ratio. This behavior is consistent with the greater ability of the more soluble $\mathrm{TBABr}$ to displace the coordination equilibrium towards the $\left[\mathrm{Fe}^{\mathrm{II}} \mathrm{Br}_{4}\right]^{2-}$ species $\left(K_{2}\right.$ in Erreur ! Référence non valide pour un signet.), thus reducing the available amount of the active tricoordinated $\left[\mathrm{FeBr}_{3}\right]^{-}$ complex. The less soluble $\mathrm{KBr}$, on the other hand, does not provide a sufficient mass effect to accomplish this transformation, while being able to produce $\mathrm{K}\left[\mathrm{FeBr}_{3}(\mathrm{MMA})\right]^{-}$extensively via equilibrium $K_{1}$ in Erreur ! Référence non valide pour un signet.. In this respect, as shown in the previous section, the solubility of $\mathrm{KFeBr}_{3}$ is greater than that of $\mathrm{FeBr}_{2}$ and much greater than that of $\mathrm{KBr}$.

Scheme 2). The weak coordinating power of MMA insures its rapid dissociation during the atom transfer activation process.

It is of interest to compare our experimental results for the polymerization rate as a function of $\mathrm{Br} / \mathrm{FeBr}_{2}$ ratio with those reported in the literature. For our $\mathrm{FeBr}_{2} / \mathrm{KBr}$ system, the amount of bromide salt does not affect the rate when added in greater amounts than 1 equivalent per $\mathrm{FeBr}_{2}$ (Figure 2). On the other hand, Matyjaszewski et al. ${ }^{32}$ have shown that the rate of the $\mathrm{FeBr}_{2} /\left[n \mathrm{Bu}_{4} \mathrm{E}\right] \mathrm{Br}$-catalyzed $(\mathrm{E}=\mathrm{N}, \mathrm{P}) \mathrm{MMA}$ polymerization (as well as those of styrene and MA) decreases upon increasing the salt/ $\mathrm{FeBr}_{2}$ ratio. This behavior is consistent with the greater ability of the more soluble $\mathrm{TBABr}$ to displace the coordination equilibrium towards the $\left[\mathrm{Fe}^{\mathrm{II}} \mathrm{Br}_{4}\right]^{2-}$ species $\left(K_{2}\right.$ in Erreur ! Référence non valide pour un signet.), thus reducing the available amount of the active tricoordinated $\left[\mathrm{FeBr}_{3}\right]^{-}$ complex. The less soluble $\mathrm{KBr}$, on the other hand, does not provide a sufficient mass effect to accomplish this transformation, while being able to produce $\mathrm{K}\left[\mathrm{FeBr}_{3}(\mathrm{MMA})\right]^{-}$extensively via equilibrium $K_{1}$ in Erreur ! Référence non valide pour un signet.. In this respect, as shown in the previous section, the solubility of $\mathrm{KFeBr}_{3}$ is greater than that of $\mathrm{FeBr}_{2}$ and much greater than that of $\mathrm{KBr}$.

Scheme 2. Moderating ATRP equilibrium by $\mathrm{FeBr}_{2}$ in the presence of bromide salts.
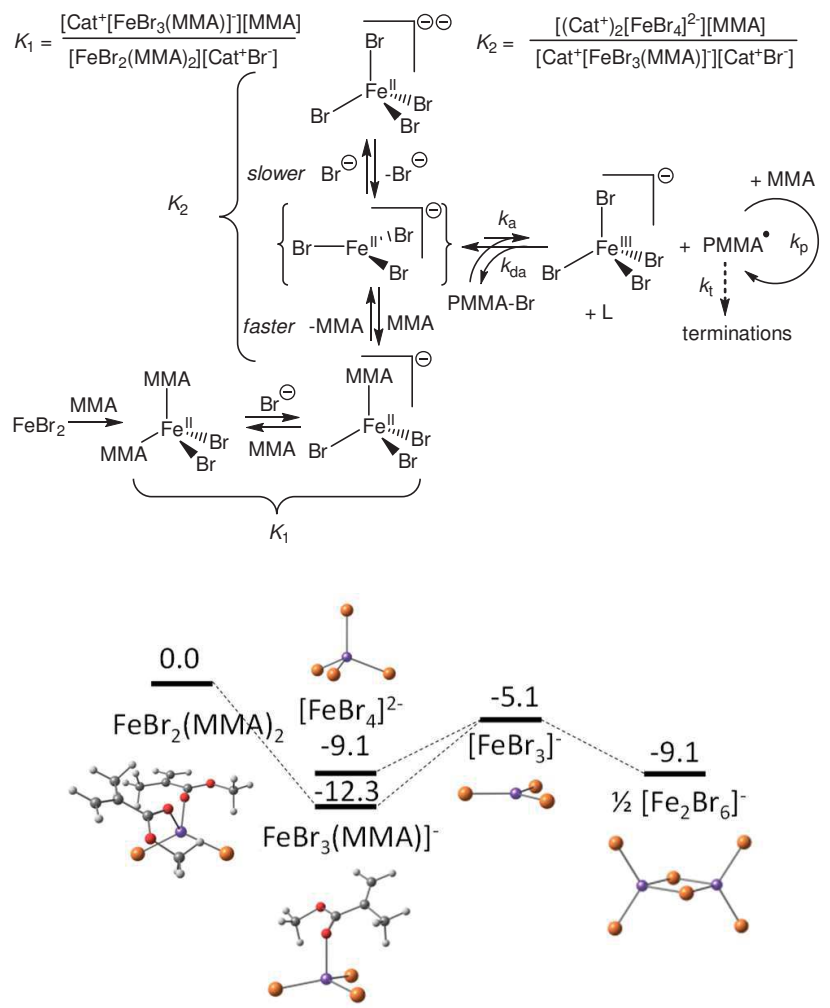

Figure 7. DFT-calculated Gibbs energy changes (in kcal mol-1), for the addition of the bromide ion to complex [ $\left.\mathrm{FeBr}_{2}(\mathrm{MMA})_{2}\right]$, obtained using the $6-31+\mathrm{G}^{* *}$ basis set for the $\mathrm{Br}$ atom

In order to further substantiate the above propositions, calculations of equilibria involving MMA and $\mathrm{Br}^{-}$coordination to $\mathrm{FeBr}_{2}$ were conducted by the DFT approach to obtain relative Gibbs energies in the standard state $\left(298 \mathrm{~K}, 1 \mathrm{~mol} \mathrm{~L}^{-1}\right)$ in MMA solution, using a polarizable continuum model to take solvation effects into account, but did not consider the interaction with the cation (see the Experimental section for details). All calculations were carried out for the high-spin $(S=2)$ configuration, as experimentally established for coordination compounds of $\mathrm{FeBr}_{2}$ with weak field ligands. ${ }^{71}$ The more reliable results obtained with the higher quality $6-31+\mathrm{G}^{* *}$ basis set for the $\mathrm{Br}$ atom are summarized in Figure 7 (other computational results are compared in the SI section, see Figure $\mathrm{S} 9$ and related discussion). The starting $\left[\mathrm{FeBr}_{2}(\mathrm{MMA})_{2}\right]$ complex, which serves as a reference point, optimized to a tetrahedral geometry as expected. Exchange of one MMA ligand with bromide, yielding the anionic $\left[\mathrm{FeBr}_{3}(\mathrm{MMA})\right]^{-}$ complex, provides a stabilization of $12.3 \mathrm{kcal} \mathrm{mol}^{-1}$. The 
MMA coordination is quite weak, since dissociation to yield the putative tricoordinated $\left[\mathrm{FeBr}_{3}\right]^{-}$costs only $7.2 \mathrm{kcal} \mathrm{mol}^{-1}$. Weak MMA coordination is also clearly indicated by the optimized geometry, with a relatively long Fe-O distance and a flattened $\mathrm{FeBr}_{3}^{-}$moiety (see the optimized parameters in Table S11 and discussion in the SI). The unsaturated $\left[\mathrm{FeBr}_{3}\right]^{-}$ intermediate can be stabilized by coordination of an additional bromide ion with a gain of $4.0 \mathrm{kcal} \mathrm{mol}^{-1}$ or by dimerization with the same Gibbs energy gain, but these are not as effective as the stabilization by MMA coordination. Thus, the most stable structure in the $\mathrm{FeBr}_{2} / \mathrm{MMA} / \mathrm{Br}^{-}$system, even in the presence of excess bromide, is suggested by these calculations to be the anionic $\left[\mathrm{FeBr}_{3}(\mathrm{MMA})\right]^{-}$complex. To the best of our knowledge, none of the previously reported investigations on $\mathrm{FeX}_{2}-\mathrm{X}^{-}$catalyzed ATRP $(\mathrm{X}=\mathrm{Cl}, \mathrm{Br})$ have provided concrete evidence of the nature of the catalytically active species, nor made the proposition that this may be a monoanionic $\left[\mathrm{FeX}_{3}(\mathrm{~L})\right]^{-}$complex.

The key action of the bromide anion in promoting the $\mathrm{FeBr}_{2}$ catalytic activity can be understood on the basis of the computational results: $\mathrm{Br}^{-}$coordination labilizes the MMA ligand, thus kinetically helping its dissociation, which is needed during the atom transfer activation. This rationalizes the greater catalytic activity of $\left[\mathrm{FeBr}_{3}(\mathrm{MMA})\right]^{-}$relative to the neutral $\left[\mathrm{FeBr}_{2}(\mathrm{MMA})_{2}\right]$ complex. The calculations suggest that the $\left[\mathrm{FeBr}_{3}\right]^{-}$intermediate is better stabilized by MMA coordination, yielding complex $\left[\mathrm{FeBr}_{3}(\mathrm{MMA})\right]^{-}$back, than by additional $\mathrm{Br}^{-}$to yield $\left[\mathrm{FeBr}_{4}\right]^{2-}$, although this relative stabilization is very sensitive to the computational level (see SI) and we should also underline that the effect of ion pairing with the cation was not considered in the calculations. Ion pairing indeed appears to have a significant effect, as shown by the much faster $k_{\text {obs }}$ in the presence of the much less soluble $\mathrm{K}(18 \mathrm{C} 6)^{+}$salt. As is well-established, ${ }^{1-9} k_{\text {obs }}$ is proportional to $k_{\mathrm{p}}$, to $K_{\mathrm{ATRP}}\left(=k_{\mathrm{a}} / k_{\mathrm{da}}\right)$, and to the $\left[\mathrm{Fe}^{\mathrm{II}}\right] /\left[\mathrm{Fe}^{\mathrm{III}}\right]$ ratio (all constants are defined in It is of interest to compare our experimental results for the polymerization rate as a function of $\mathrm{Br}^{-}$ $/ \mathrm{FeBr}_{2}$ ratio with those reported in the literature. For our $\mathrm{FeBr}_{2} / \mathrm{KBr}$ system, the amount of bromide salt does not affect the rate when added in greater amounts than 1 equivalent per $\mathrm{FeBr}_{2}$ (Figure 2). On the other hand, Matyjaszewski et al. ${ }^{32}$ have shown that the rate of the $\mathrm{FeBr}_{2} /\left[n \mathrm{Bu}_{4} \mathrm{E}\right] \mathrm{Br}$-catalyzed (E $=\mathrm{N}, \mathrm{P}$ ) MMA polymerization (as well as those of styrene and MA) decreases upon increasing the salt $/ \mathrm{FeBr}_{2}$ ratio. This behavior is consistent with the greater ability of the more soluble $\mathrm{TBABr}$ to displace the coordination equilibrium towards the $\left[\mathrm{Fe}^{\mathrm{II}} \mathrm{Br}_{4}\right]^{2-}$ species $\left(K_{2}\right.$ in Erreur ! Référence non valide pour un signet.), thus reducing the available amount of the active tricoordinated $\left[\mathrm{FeBr}_{3}\right]^{-}$complex. The less soluble $\mathrm{KBr}$, on the other hand, does not provide a sufficient mass effect to accomplish this transformation, while being able to produce $\mathrm{K}\left[\mathrm{FeBr}_{3}(\mathrm{MMA})\right]^{-}$extensively via equilibrium $K_{1}$ in Erreur ! Référence non valide pour un signet.. In this respect, as shown in the previous section, the solubility of $\mathrm{KFeBr}_{3}$ is greater than that of $\mathrm{FeBr}_{2}$ and much greater than that of $\mathrm{KBr}$.

Scheme 2). The propagation rate constant $k_{\mathrm{p}}$ is not affected by the catalyst nature and it is hard to believe that the presence of crown ether reduces dramatically the generation of the $\mathrm{Fe}^{\mathrm{III}}$ deactivator. Therefore, it is likely that the cation strongly affects the ATRP equilibrium position. A low permittivity medium such as neat MMA most probably does not allow the extensive generation of free ions, hence the catalyst is likely to be mostly present in the form of ion pairs. The ion pairing in
$\mathrm{K}^{+}\left[\mathrm{Fe}^{\mathrm{II}} \mathrm{Br}_{3}(\mathrm{MMA})\right]^{-}$and $\mathrm{K}^{+}\left[\mathrm{Fe}^{\mathrm{II}} \mathrm{Br}_{4}\right]^{-}$(where $\mathrm{K}^{+}$is probably surrounded by a number of MMA molecules) must therefore energetically stabilize the $\mathrm{Fe}^{\mathrm{II}}$ species, relatively to the $\mathrm{Fe}^{\mathrm{II}}$ species, to a greater extent than the ion pairing in $\mathrm{K}(18 \mathrm{C} 6)^{+}\left[\mathrm{Fe}^{\mathrm{II}} \mathrm{Br}_{3}(\mathrm{MMA})\right]^{-}$and $\mathrm{K}(18 \mathrm{C} 6)^{+}\left[\mathrm{Fe}^{\mathrm{III}} \mathrm{Br}_{4}\right]^{-}$.

\section{Polymerizations with salts of other anions.}

The effect of additional inorganic salts, representative of those used in our recent study of EBrPA activation, were also tested in combination with $\mathrm{FeBr}_{2}$. The results with the lighter alkali metal chlorides, run in the presence of 0.1 equivalents of $\mathrm{FeBr}_{3}$, are shown in Figure 8 (raw data in Table S13). As for the corresponding light alkali metal bromides, the chlorides yield well controlled polymerizations with relatively similar $k_{\text {obs }}$ to those of the corresponding bromides. The lithium salt gives once again the fastest polymerization, but the $\mathrm{K}$ system is in this case faster than the $\mathrm{Na}$ one and almost as fast as the $\mathrm{Li}$ one. The polymerizations run in the absence of $\mathrm{FeBr}_{3}$ show the same phenomena already discussed above for the bromide system (non-zero intercept, $k_{\mathrm{obs}}$ close to those measured with $\mathrm{FeBr}_{3}$, see Figure S10). A kinetic experiment was also run in the presence of $\mathrm{CaCl}_{2}$, but only in the absence of $\mathrm{FeBr}_{3}$, yielding a slightly slower polymerization but still with good control (Figure S11). The corresponding polymerization with $\mathrm{MgCl}_{2}$, run under the same conditions was even slower $(21.7 \%$ conversion after $1.5 \mathrm{~h}$ ) but still gave a quite well-controlled process $\left(M_{\mathrm{n}}=4900 \mathrm{~g} \mathrm{~mol}^{-1}\right.$ vs. a theoretical molar mass of $4345 \mathrm{~g}$ $\mathrm{mol}^{-1}$, with $\left.Ð=1.17\right)$. In these polymerization, it is likely that the mixed halide $\left[\mathrm{Fe}^{\mathrm{III}} \mathrm{ClBr}_{3}\right]^{-}$deactivator, resulting from the activation of the bromine-terminated chains by $\left[\mathrm{Fe}^{\mathrm{II}} \mathrm{ClBr}_{2}\right]^{-}$, produces chlorine-terminated chains, similar to what was shown in the polymerization of MMA from a Br-terminated PMA macroinitiator when using $\mathrm{Cu}^{\mathrm{I}} \mathrm{Cl}$ as catalyst. ${ }^{72}$
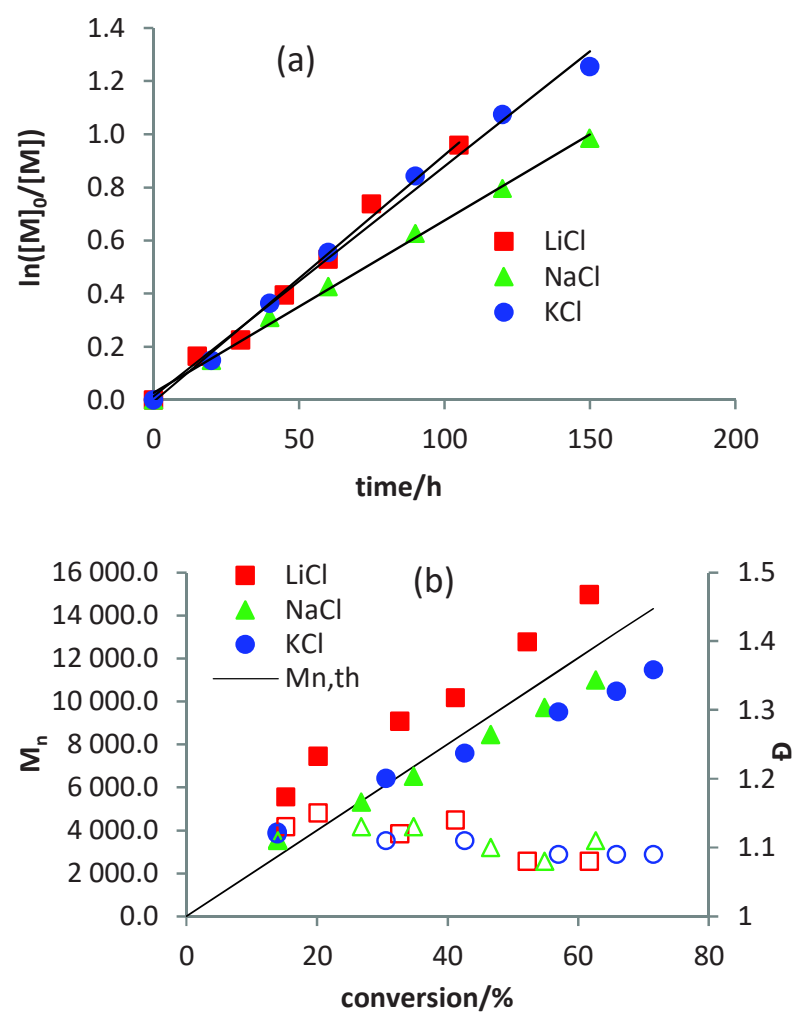
Figure 8. First-order plots (a) and evolution of $M_{\mathrm{n}}$ and $Ð$ with conversion (b) for the EBrPA-initiated bulk MMA polymerizations with $\mathrm{FeBr}_{2}-\mathrm{MtCl}$ activation $(\mathrm{Mt}=\mathrm{Li}, \mathrm{Na}, \mathrm{K})$ in the presence of $\mathrm{FeBr}_{3}$ ([MMA]:[ $\left.\mathrm{FeBr}_{2}\right]:\left[\mathrm{FeBr}_{3}\right]:[\mathrm{EBrPA}]:[\mathrm{MtCl}]=$ 200:1:0.1:1:2) at $70^{\circ} \mathrm{C}$.

Controlled polymerizations were also observed in the presence of iodide salts ( $\mathrm{NaI}$ and $\mathrm{KI}$ ), with slightly lower $k_{\mathrm{obs}}$ than those of the corresponding chlorides and bromides. The data are collected in Table S14 and Figure S12. The observed rate constants for the three halides $(\mathrm{Cl}, \mathrm{Br}, \mathrm{I})$, measured in the absence of $\mathrm{FeBr}_{3}$, are respectively (in $10^{3} \mathrm{~min}^{-1}$ ): 6.9, 11.5 and 5.9 for the Na salts, 6.4, 11.6 and 4.7 for the K salts, and 10.5 and 21.7 for the Li chloride and bromide. Note, however, that a comparison of these rates is not very meaningful because the observed rate constants are affected by the extent of initial terminations, producing $\mathrm{FeBr}_{3}$, as well as by halide exchange. ${ }^{47}$ The presence of salts with non-coordinating anions $\left(\mathrm{KPF}_{6}\right.$ and LiOTf) polymerizations led to significantly slower polymerizations (Table S15 and Figure S13), though faster than the $\mathrm{FeBr}_{2}$ control without additives (Table 1, entry 8 ), and proceeded again with quite good control. For instance, lithium triflate system gave a $35 \%$ conversion after $6 \mathrm{~h}$ at $70^{\circ} \mathrm{C}$, using again bulk conditions with an $\mathrm{MMA} / \mathrm{FeBr}_{2} / \mathrm{EBrPA} / \mathrm{LiOTf}$ molar ratio of 200:1:1:2. This demonstrates that even these weakly coordinating anions are able to interact with $\mathrm{FeBr}_{2}$ and provide more active ATRP catalysts. Given the relative low rates of these processes, they were not optimized by addition of $\mathrm{FeBr}_{3}$. Polymerizations run in the presence of weakly coordinating anions have been previously reported, but only in polar solvents. ${ }^{25}$ The alkali metal sulfates gave even slower (in the order $\mathrm{Na}>\mathrm{K}>\mathrm{Rb}>\mathrm{Cs}$ ) and more poorly controlled polymerizations, requiring $12 \mathrm{~h}$ to reach a $50 \%$ monomer consumption at $90{ }^{\circ} \mathrm{C}$ for the faster $\mathrm{Na}_{2} \mathrm{SO}_{4}$ system, see Table $\mathrm{S} 15$. Finally, the polymerizations run in the presence of $\mathrm{NaNO}_{3}, \mathrm{KNO}_{3}$ and $\mathrm{NaHSO}_{4}$ as additives gave no conversion whatsoever. In these cases, the polymerization mixtures showed a rapid color change, suggesting that the $\mathrm{FeBr}_{2}$ catalyst undergoes oxidation to $\mathrm{Fe}^{\mathrm{III}}$. This was confirmed by a UV-visible study, see Figure S14. Thus, no polymerization may occur because the activator is quantitatively converted into the deactivator. Oxidation of $\mathrm{Fe}^{\mathrm{II}}$ by nitrate salts is not surprising, since $\mathrm{Fe}^{\mathrm{II}}$ nitrate is known to autodecompose to $\mathrm{Fe}^{\mathrm{III}}$ products at high temperatures. ${ }^{73}$ Oxidation by $\mathrm{NaHSO}_{4}$ contrasts with the stability in the presence of the corresponding sulfate and may be attributed to the increase of the sulfate oxidizing ability in a more acidic environment.

\section{Polymerizations with inorganic bases}

Investigations were also conducted in the presence of inorganic bases, comprising hydroxides $(\mathrm{NaOH}, \mathrm{KOH})$, carbonates $\left(\mathrm{Na}_{2} \mathrm{CO}_{3}, \mathrm{~K}_{2} \mathrm{CO}_{3}\right)$, bicarbonates $\left(\mathrm{NaHCO}_{3}, \mathrm{KHCO}_{3}\right)$ and the sodium phosphates $\left(\mathrm{Na}_{3} \mathrm{PO}_{4}, \mathrm{Na}_{2} \mathrm{HPO}_{4}\right.$ and $\left.\mathrm{NaH}_{2} \mathrm{PO}_{4}\right)$. These studies were motivated by the established promoting effect of inorganic bases in $\mathrm{FeX}_{2}$-catalyzed ATRP processes $(\mathrm{X}=\mathrm{Cl}, \mathrm{Br})$, although all published contributions involved the simultaneous presence of other ligands, e.g. $\mathrm{TBABr}$ for the $\mathrm{NaOH}$ - and $\mathrm{Fe}(\mathrm{OH})_{3}$-promoted AGET bulk polymerization of styrene $^{39}$ as well as for the $\mathrm{NaOH}, \mathrm{BMImOH}, \mathrm{Na}_{2} \mathrm{CO}_{3}, \mathrm{Na}-$ $\mathrm{HCO}_{3}$, or $\mathrm{Na}_{3} \mathrm{PO}_{4}$-promoted AGET bulk polymerization of MMA, ${ }^{42,}{ }^{44}$ and deep eutectic solvents for the $\mathrm{Na}_{2} \mathrm{CO}_{3}$ promoted MMA ATRP. ${ }^{31}$ In the latter case, the solvent itself may play a ligand role. It is also relevant to note that, in a single case, the promoting effect of bases in the absence of any other ligand was highlighted for the AGET MMA bulk polymerization. However, that investigation used bases containing an organic cation: $\mathrm{BMImOH},(\mathrm{BMIm})_{2} \mathrm{CO}_{3}$, $(\mathrm{BMim}) \mathrm{HCO}_{3}$ and $(\mathrm{BMIm})_{3} \mathrm{PO}_{4}{ }^{43}$ It was therefore of interest to verify whether purely inorganic bases may be able to promote, by themselves, the catalytic activity of $\mathrm{FeBr}_{2}$ for the bulk MMA ATRP.

Initial experiments carried out without any additional $\mathrm{FeBr}_{3}$ at the slightly lower temperature of $60^{\circ} \mathrm{C}$ gave, as for the above-described polymerization with other inorganic salts, high polymerization rates and good control, with $M_{\mathrm{n}}$ close to target and low $Ð$ in all cases (Table S16 and Figure S15). The $k_{\text {obs }}$ is highest with $\mathrm{NaOH}\left(8.6 \cdot 10^{-3} \mathrm{~min}^{-1}\right)$, but all hydroxides, carbonates and bicarbonates gave relatively fast polymerizations. The phosphate systems are slower, in the order $\mathrm{Na}_{3} \mathrm{PO}_{4}$ $>\mathrm{Na}_{2} \mathrm{HPO}_{4}>\mathrm{NaH}_{2} \mathrm{PO}_{4}$. In addition, $\mathrm{Na}_{3} \mathrm{PO}_{4}$ showed an induction phenomenon. Tests with variable $\mathrm{FeBr}_{2} /$ base ratios were conducted for the $\mathrm{Na}_{2} \mathrm{CO}_{3}$ system yielding, like for the $\mathrm{KBr}$ system, an increase of polymerization rate up to a 1:1 molar ratio and subsequent stagnation (Table S17 and Figure S16). This suggests that the active species for the carbonate system is again a 1:1 complex. The presence of small amounts of water (2 equivalents per $\mathrm{FeBr}_{2}$ ) has a weak effect on the polymerization rate, although more significant than in the case of the $\mathrm{FeBr}_{2}-\mathrm{KBr}$ system discussed above, whereas using 60 equivalents of water greatly reduced the rate, for the same reason (precipitation of the iron catalyst), see Table S16 and Figure S17.

The experiments with the $\mathrm{Na}$ and $\mathrm{K}$ hydroxide, carbonate and bicarbonate were repeated in the presence of 0.1 equivalent of $\mathrm{FeBr}_{3}$, yielding the results shown in Table S18 and Figure 9 . All bases gave similar polymerization rates $\left(k_{\text {obs }}\right.$ in the narrow 0.0025-0.004 $\mathrm{min}^{-1}$ range) and a better control relative to the corresponding experiments in which $\mathrm{FeBr}_{3}$ was not initially present, with dispersities around 1.1 or lower.
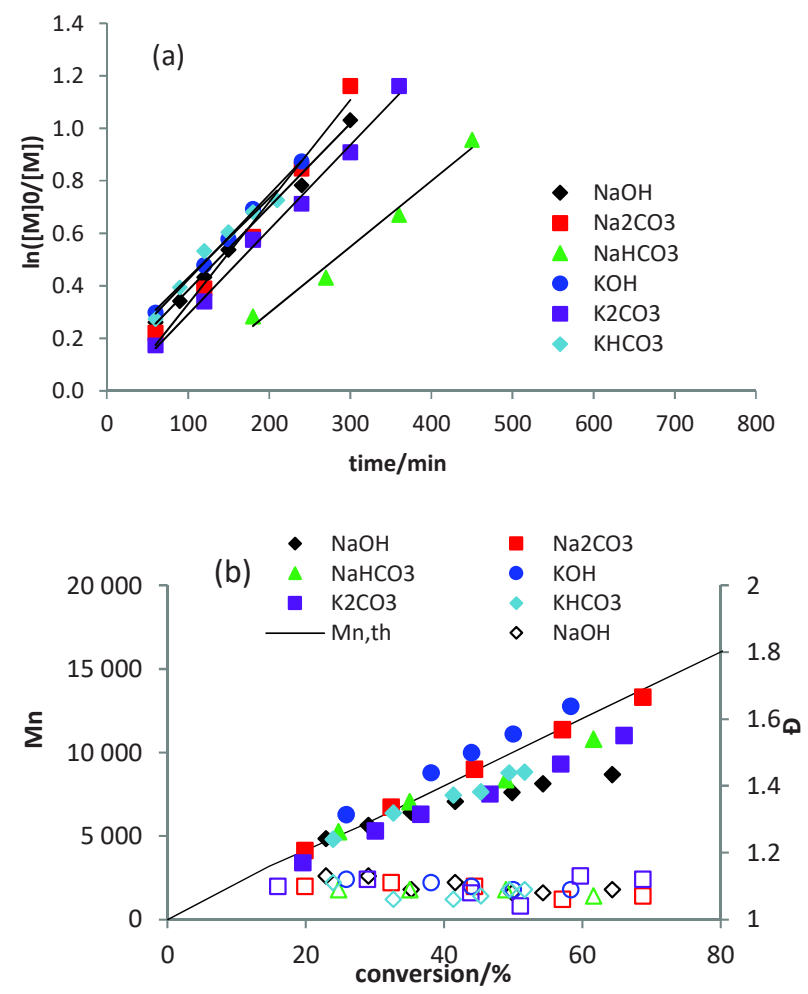
Figure 9. First-order plots (a) and evolution of $M_{\mathrm{n}}$ and $Ð$ with conversion (b) for the EBrPA-initiated bulk MMA polymerizations with $\mathrm{FeBr}_{2}$-base activation (base $=\mathrm{Na}$ or $\mathrm{K}$ hydroxide carbonate or bicarbonate) in the presence of $\mathrm{FeBr}_{3}$ $\left([\mathrm{MMA}]:\left[\mathrm{FeBr}_{2}\right]:\left[\mathrm{FeBr}_{3}\right]:[\mathrm{EBrPA}]:[\right.$ base $\left.]=200: 1: 0.1: 1: 2\right)$ at $60^{\circ} \mathrm{C}$.

\section{Polymerizations of other monomers}

A limited number of experiments were also conducted with methyl and $n$-butyl acrylate (MA, BA) and $n$-butyl methacrylate (BMA), in order to establish the potential generality of this simplified ATRP protocol. Initial tests, carried out in the presence of $\mathrm{Na}_{2} \mathrm{CO}_{3}$, gave relatively rapid but poorly controlled polymerizations of the acrylates, with $M_{\mathrm{n}}$ much greater than expected and high $Ð$ (see details in Table S19), whereas the BMA polymerization gave more promising results. Additional polymerizations were therefore conducted only for BMA. Using $\mathrm{KOH}$ and $\mathrm{KBr}$ as additives, the polymerizations were relatively well controlled, with good agreement between measured and expected $M_{\mathrm{n}}$ values. However, the resulting $D$ values (1.19-1.34 at high conversions) were higher than those obtained for MMA under the same conditions, see Table S20.

\section{Conclusion}

In this contribution, we have shown that simpler procedures than previously reported ones for the $\mathrm{FeBr}_{2}$-catalyzed ATRP of methyl methacrylate lead to better results (faster polymerizations, equal or better control of the molecular weight and molecular weight distribution). Using simple inorganic salts as catalyst promoters, rather than salts of large organic cations or neutral ligand additives, has several advantages, which include facile availability, reduced cost, and reduced toxicity. Keys to the performance of these inorganic salts are the significant solubility of the activated catalyst, e.g. $\mathrm{KFeBr}_{3}$, in the bulk monomer and participation of the cation, through ion pairing with the anionic activator and with the anionic deactivator, in modulating the atom transfer equilibrium. This was clearly shown by the different activity of $\mathrm{FeBr}_{2} / \mathrm{MtBr}$ with different Mt cations ( $\mathrm{Li}, \mathrm{Na}, \mathrm{K}, \mathrm{Rb}, \mathrm{Cs}$ ) and also by the effect of the addition of 18-crown-6 to the $\mathrm{KBr}$ system. Interestingly, the $\mathrm{K}(18 \mathrm{C} 6)^{+}$system is less soluble and at the same time more active. Finally, the combination of the experimental results and the DFT calculations has identified the tricoordinated $\left[\mathrm{FeBr}_{3}\right]^{-}$intermediate, which is weakly stabilized by MMA coordination, as the active catalyst.

\section{ASSOCIATED CONTENT}

Supporting Information. Details of polymerization kinetics, UV-visible spectra and DFT calculations (23 pages). This material is available free of charge via the Internet at http://pubs.acs.org.

\section{AUTHOR INFORMATION}

\section{Corresponding Author}

* Prof. Zhigang Xue, zgxue@ mail.hust.edu.cn

* Prof. Rinaldo Poli, rinaldo.poli@1cc-toulouse.fr

\section{Author Contributions}

All authors have given approval to the final version of the manuscript.

\section{Funding Sources}

National Natural Science Foundation of China (51622303); Natural Science Foundation of Hubei Scientific Committee (2018CFA059 and 2016CFA001).

\section{ACKNOWLEDGMENT}

This work was financially supported by the National Natural Science Foundation of China (51622303) and Natural Science Foundation of Hubei Scientific Committee (2018CFA059 and 2016CFA001). We also gratefully acknowledge the CNRS (Centre National de la Recherche Scientifique) for recurrent funding and the China Scholarship Council for a doctoral fellowship to JW (No. 201806160052). This work was granted access to the computational resources of the CICT (Centre Interuniversitaire de Calcul de Toulouse, project CALMIP).

\section{ABBREVIATIONS}

ATRP, atom transfer radical polymerization; EBrPA, ethyl $\alpha$ bromophenylacetate; MMA, methyl methacrylate; PRE, persistent radical effect.

\section{REFERENCES}

1. Kamigaito, M.; Ando, T.; Sawamoto, M. Metal-catalyzed living radical polymerization. Chem. Rev. 2001, 101 (12), 3689-3745.

2. Matyjaszewski, K.; Xia, J. H. Atom transfer radical polymerization. Chem. Rev. 2001, 101 (9), 2921-2990.

3. Ouchi, M.; Terashima, T.; Sawamoto, M. Transition MetalCatalyzed Living Radical Polymerization: Toward Perfection in Catalysis and Precision Polymer Synthesis. Chem. Rev. 2009, 109 (11), 4963-5050.

4. di Lena, F.; Matyjaszewski, K. Transition metal catalysts for controlled radical polymerization. Progr. Polym. Sci. 2010, 35 (8), 959-1021.

5. Matyjaszewski, K.; Tsarevsky, N. V. Macromolecular Engineering by Atom Transfer Radical Polymerization. J. Am. Chem. Soc. 2014, 136 (18), 6513-6533 DOI: 10.1021/ja408069v.

6. Matyjaszewski, K. Atom Transfer Radical Polymerization (ATRP): Current Status and Future Perspectives. Macromolecules 2012, 45 (10), 4015-4039 DOI: 10.1021/ma3001719.

7. Boyer, C.; Corrigan, N. A.; Jung, K.; Nguyen, D.; Nguyen, T.-K.; Adnan, N. N. M.; Oliver, S.; Shanmugam, S.; Yeow, J. Copper-Mediated Living Radical Polymerization (Atom Transfer Radical Polymerization and Copper(0) Mediated Polymerization): From Fundamentals to Bioapplications. Chem. Rev. 2016, 116 (4), 1803-1949 DOI: 10.1021/acs.chemrev.5b00396.

8. Lutz, J.-F.; Lehn, J.-M.; Meijer, E. W.; Matyjaszewski, K. From precision polymers to complex materials and systems. Nat. Rev. Mater. 2016, 1 (5), 16024 DOI: 10.1038/natrevmats.2016.24.

9. Ren, J. M.; McKenzie, T. G.; Fu, Q.; Wong, E. H. H.; Xu, J.; An, Z.; Shanmugam, S.; Davis, T. P.; Boyer, C.; Qiao, G. G. Star Polymers. Chem. Rev. 2016, 116 (12), 6743-6836 DOI: 10.1021/acs.chemrev.6b00008.

10. Tang, W.; Kwak, Y.; Braunecker, W.; Tsarevsky, N. V.; Coote, M. L.; Matyjaszewski, K. Understanding atom transfer radical polymerization: Effect of ligand and initiator structures on the equilibrium constants. J. Am. Chem. Soc. 2008, 130 (32), 1070210713.

11. Ribelli, T. G.; Fantin, M.; Daran, J.-C.; Augustine, K. F.; Poli, R.; Matyjaszewski, K. Synthesis and Characterization of the Most Active Copper-based ATRP Catalyst based on tris[(4dimethylaminopyridyl)methyl]amine $J$. Am. Chem. Soc. 2018, 140, $1525-1534$.

12. Ribelli, T. G.; Lorandi, F.; Fantin, M.; Matyjaszewski, K. Atom Transfer Radical Polymerization: Billion Times More Active Catalysts and New Initiation Systems. Macromol. Rapid Comm. 2019, 40 (1), 1800616 DOI: 10.1002/marc.201800616.

13. Tang, H. D.; Arulsamy, N.; Radosz, M.; Shen, Y. Q.; Tsarevsky, N. V.; Braunecker, W. A.; Tang, W.; Matyjaszewski, K. 
Highly active copper-based catalyst for atom transfer radical polymerization. J. Am. Chem. Soc. 2006, 128 (50), 16277-16285.

14. Zhang, Q.; Wilson, P.; Li, Z.; McHale, R.; Godfrey, J.; Anastasaki, A.; Waldron, C.; Haddleton, D. M. Aqueous CopperMediated Living Polymerization: Exploiting Rapid Disproportionation of CuBr with Me6TREN. J. Am. Chem. Soc. 2013, 135 (19), 7355-7363 DOI: 10.1021/ja4026402.

15. Poli, R.; Allan, L. E. N.; Shaver, M. P. Iron-Mediated Reversible Deactivation Radical Polymerisation. Prog. Polym. Sci. 2014, 39, 1827-1845.

16. Xue, Z.; He, D.; Xie, X. Iron-catalyzed atom transfer radical polymerization. Polym. Chem. 2015, 6 (10), 1660-1687 DOI: 10.1039/c4py01457j.

17. Grishin, D. F.; Grishin, I. D. Iron-based catalytic systems in atom-transfer controlled-radical-polymerization processes. Polym. Sci. Ser. C 2015, 57 (1), 32-64 DOI: 10.1134/s1811238215010038.

18. Simakova, A.; Mackenzie, M.; Averick, S. E.; Park, S.; Matyjaszewski, K. Bioinspired Iron-Based Catalyst for Atom Transfer Radical Polymerization. Angew. Chem. Int. Ed. 2013, 52, 1214812151 DOI: $10.1002 /$ anie. 201306337

19. Pan, X.; Malhotra, N.; Zhang, J.; Matyjaszewski, K. Photoinduced Fe-Based Atom Transfer Radical Polymerization in the Absence of Additional Ligands, Reducing Agents, and Radical Initiators. Macromolecules 2015, 48 (19), 6948-6954 DOI: 10.1021/acs.macromol.5b01815.

20. Schroeder, H.; Buback, M. SP-PLP-EPR Measurement of Iron-Mediated ATRP Deactivation Rate. Macromolecules 2015, 48 (17), 6108-6113 DOI: 10.1021/acs.macromol.5b01270.

21. Schroeder, H.; Matyjaszewski, K.; Buback, M. Kinetics of Fe-mediated ATRP with triarylphosphines. Macromolecules 2015, 48 (13), 4431-4437.

22. Shen, Y.; Tang, H.; Ding, S. Catalyst separation in atom transfer radical polymerization. Prog. Polym. Sci. 2004, 29 (10), 1053-1078 DOI: 10.1016/j.progpolymsci.2004.08.002.

23. Schroder, K.; Matyjaszewski, K.; Noonan, K. J. T.; Mathers, R. T. Towards sustainable polymer chemistry with homogeneous metal-based catalysts. Green Chem. 2014, 16 (4), 16731686 DOI: $10.1039 / \mathrm{C} 3 \mathrm{GC} 42159 \mathrm{G}$.

24. Bauer, I.; Knölker, H.-J. Iron Catalysis in Organic Synthesis. Chem. Rev. 2015, 115 (9), 3170-3387 DOI: $10.1021 /$ cr500425u.

25. Wang, Y.; Matyjaszewski, K. ATRP of MMA in Polar Solvents Catalyzed by $\mathrm{FeBr} 2$ without Additional Ligand. Macromolecules 2010, 43 (9), 4003-4005 DOI: 10.1021/ma1002276.

26. Yang, D. F.; Wang, J. R.; Han, J. Y.; Khan, M. Y.; Xie, X. L.; Xue, Z. G. Initiator-Free Atom Transfer Radical Polymerization of Methyl Methacrylate Based on $\mathrm{FeBr}_{3}\left(\mathrm{PPh}_{3}\right)_{\mathrm{n}}$ System. J. Polym. Sci., Polym. Chem. 2017, 55 (23), 3842-3850 DOI: 10.1002/pola.28768.

27. Yang, D. F.; He, D.; Liao, Y. G.; Xue, Z. G.; Zhou, X. P.; Xie, X. L. Iron-Mediated AGET ATRP of Methyl Methacrylate in the Presence of Polar Solvents as Ligands. J. Polym. Sci., Polym. Chem. 2014, 52 (7), 1020-1027 DOI: 10.1002/pola.27083.

28. Xue, Z. G.; Zhou, J.; He, D.; Wu, F.; Yang, D. F.; Ye, Y. S.; Liao, Y. G.; Zhou, X. P.; Xie, X. L. Iron-catalyzed AGET ATRP of methyl methacrylate using an alcohol as a reducing agent in a polar solvent. Dalton Trans. 2014, 43 (43), 16528-16533 DOI: 10.1039/c4dt01256a.

29. Zhou, J.; Wang, J. R.; Han, J. Y.; He, D.; Yang, D. F.; Xue, Z. G.; Liao, Y. G.; Xie, X. L. Amide group-containing polar solvents as ligands for iron-catalyzed atom transfer radical polymerization of methyl methacrylate. Rsc Advances 2015, 5 (54), 43724-43732 DOI: 10.1039/c5ra05460e.

30. Wang, J. R.; Tian, M. Y.; Li, S. Q.; Wang, R.; Du, F. P.; Xue, Z. G. Ligand- free iron- based electrochemically mediated atom transfer radical polymerization of methyl methacrylate. Polym. Chem. 2018, 9 (34), 4386-4394 DOI: 10.1039/c8py00933c.

31. Wang, J. R.; Han, J. Y.; Khan, M. Y.; He, D.; Peng, H. Y.; Chen, D. Y.; Xie, X. L.; Xue, Z. G. Deep eutectic solvents for green and efficient iron-mediated ligand-free atom transfer radical polymerization. Polym. Chem. 2017, 8 (10), 1616-1627 DOI: 10.1039/c6py02066f
32. Teodorescu, M.; Gaynor, S. G.; Matyjaszewski, K. Halide anions as ligands in iron-mediated atom transfer radical polymerization. Macromolecules 2000, 33 (7), 2335-2339.

33. Sarbu, T.; Matyjaszewski, K. ATRP of Methyl Methacrylate in the Presence of Ionic Liquids with Ferrous and Cuprous Anions. Macromol. Chem. Phys. 2001, 202 (17), 3379-3391 DOI: macp3379>3.0.co;2-3 10.1002/1521-3935(20011101)202:17<3379::aid-

34. Wang, G.; Zhu, X.; Cheng, Z.; Zhu, J. Atom Transfer Radical Polymerization of Styrene Using Various Onium Salts as Ligands. J. Macromol. Sci., Pure Appl. Chem. 2004, A41 (Copyright (C) 2013 American Chemical Society (ACS). All Rights Reserved.), 487-499 DOI: 10.1081/ma-120030920.

35. Ishio, M.; Katsube, M.; Ouchi, M.; Sawamoto, M.; Inoue, Y. Active, Versatile, and Removable Iron Catalysts with Phosphazenium Salts for Living Radical Polymerization of Methacrylates. Macromolecules 2009, 42 (1), 188-193 DOI: 10.1021/ma801762k.

36. Wang, Y.; Matyjaszewski, K. ATRP of MMA Catalyzed by $\mathrm{Fe}^{\mathrm{II}} \mathrm{Br}_{2}$ in the Presence of Triflate Anions. Macromolecules 2011, 44 (6), 1226-1228 DOI: 10.1021/ma1029357.

37. Mukumoto, K.; Li, Y. C.; Nese, A.; Sheiko, S. S.; Matyjaszewski, K. Synthesis and Characterization of Molecular Bottlebrushes Prepared by Iron-Based ATRP. Macromolecules 2012, 45 (23), 9243-9249 DOI: 10.1021/ma3020867.

38. Chen, H.; Meng, Y.; Liang, Y.; Lu, Z.; Lv, P. Application of novel ionic liquids for reverse atom transfer radical polymerization of methacrylonitrile without any additional ligand. J. Mater. Res. 2009, 24 (05), 1880-1885 DOI: doi:10.1557/jmr.2009.0199.

39. Bai, L.; Zhang, L.; Zhang, Z.; Tu, Y.; Zhou, N.; Cheng, Z.; Zhu, X. Iron-Mediated AGET ATRP of Styrene in the Presence of Catalytic Amounts of Base. Macromolecules 2010, 43 (22), 92839290 DOI: $10.1021 / \mathrm{ma1013594}$

40. Chen, H.; Liang, Y.; Liu, D. L.; Tan, Z.; Zhang, S. H.; Zheng, M. L.; Qu, R. J. AGET ATRP of acrylonitrile with ionic liquids as reaction medium without any additional ligand. Materials Science \& Engineering C-Materials for Biological Applications 2010, 30 (4), 605-609 DOI: 10.1016/j.msec.2010.02.015.

41. Bai, L. J.; Zhang, L. F.; Zhang, Z. B.; Zhu, J.; Zhou, N. C.; Cheng, Z. P.; Zhu, X. L. Alumina Additives for Fast Iron-Mediated AGET ATRP of MMA Using Onium Salt as Ligand. J. Polym. Sci., Polym. Chem. 2011, 49 (18), 3970-3979 DOI: 10.1002/pola.24837.

42. Bai, L. J.; Zhang, L. F.; Zhang, Z. B.; Zhu, J.; Zhou, N. C.; Cheng, Z. P.; Zhu, X. L. Rate-Enhanced ATRP in the Presence of Catalytic Amounts of Base: An Example of Iron-Mediated AGET ATRP of MMA. J. Polym. Sci., Polym. Chem. 2011, 49 (18), 39803987 DOI: $10.1002 /$ pola.24838.

43. Deng, Z. J.; Guo, J. N.; Qiu, L. H.; Zhou, Y. X.; Xia, L.; Yan, F. Basic ionic liquids: a new type of ligand and catalyst for the AGET ATRP of methyl methacrylate. Polym. Chem. 2012, 3 (9), 2436-2443 DOI: 10.1039/c2py20262j.

44. Deng, Z. J.; Qiu, L. H.; Bai, L. J.; Zhou, Y. X.; Lin, B. C.; Zhao, J.; Cheng, Z. P.; Zhu, X. L.; Yan, F. Basic ionic liquid/FeCl3 center dot $6 \mathrm{H} 2 \mathrm{O}$ as an efficient catalyst for AGET ATRP of methyl methacrylate. J. Polym. Sci., Polym. Chem. 2012, 50 (8), 1605-1610 DOI: $10.1002 /$ pola.25931

45. Wang, Y.; Zhang, Y.; Parker, B.; Matyjaszewski, K. ATRP of MMA with ppm Levels of Iron Catalyst. Macromolecules 2011, 44 (11), 4022-4025 DOI: 10.1021/ma200771r.

46. Mukumoto, K.; Wang, Y.; Matyjaszewski, K. Iron-Based ICAR ATRP of Styrene with ppm Amounts of (FeBr3)-Br-III and 1,1 '-Azobis(cyclohexanecarbonitrile). ACS Macro Lett. 2012, 1 (5), 599602 DOI: $10.1021 / \mathrm{mz} 3001463$.

47. Wang, J.; Han, J.; Peng, H.; Tang, X.; Zhu, J.; Liao, R.-Z.; Xie, X.; Xue, Z.; Fliedel, C.; Poli, R. Activation of a bromoalkyl ATRP initiator by a variety of inorganic salts: experiments and computations. Polym. Chem. 2019, 10, 2376-2386 DOI: 10.1039/C9PY00113A.

48. Frisch, M. J.; Trucks, G. W.; Schlegel, H. B.; Scuseria, G. E.; Robb, M. A.; Cheeseman, J. R.; Scalmani, G.; Barone, V.; Mennucci, B.; Petersson, G. A.; Nakatsuji, H.; Caricato, M.; Li, X.; 
Hratchian, H. P.; Izmaylov, A. F.; Bloino, J.; Zheng, G.; Sonnenberg, J. L.; Hada, M.; Ehara, M.; Toyota, K.; Fukuda, R.; Hasegawa, J.; Ishida, M.; Nakajima, T.; Honda, Y.; Kitao, O.; Nakai, H.; Vreven, T.; Montgomery Jr., J. A.; Peralta, J. E.; Ogliaro, F.; Bearpark, M.; Heyd, J. J.; Brothers, E.; Kudin, K. N.; Staroverov, V. N.; Kobayashi, R.; Normand, J.; Raghavachari, K.; Rendell, A.; Burant, J. C.; Iyengar, S. S.; Tomasi, J.; Cossi, M.; Rega, N.; Millam, N. J.; Klene, M.; Knox, J. E.; Cross, J. B.; Bakken, V.; Adamo, C.; Jaramillo, J.; Gomperts, R.; Stratmann, R. E.; Yazyev, O.; Austin, A. J.; Cammi, R.; Pomelli, C.; Ochterski, J. W.; Martin, R. L.; Morokuma, K.; Zakrzewski, V. G.; Voth, G. A.; Salvador, P.; Dannenberg, J. J.; Dapprich, S.; Daniels, A. D.; Farkas, Ö.; Foresman, J. B.; Ortiz, J. V.; Cioslowski, J.; Fox, D. J., Gaussian 09, Revision D.01. Gaussian, Inc.: Wallingford CT, 2009.

49. Reiher, M. Theoretical study of the Fe(phen)(2)(NCS)(2) spin-crossover complex with reparametrized density functionals. Inorg. Chem. 2002, 41 (25), 6928-6935.

50. Kim, D.; Rahaman, S. M. W.; Mercado, B. Q.; Poli, R.; Holland, P. L. The Roles of Iron Complexes in Catalytic Radical Alkene Cross-Coupling. J. Am. Chem. Soc. 2019, 141, 7473-7485 DOI: 10.1021 /jacs.9b02117.

51. Grimme, S.; Antony, J.; Ehrlich, S.; Krieg, H. A consistent and accurate $\mathrm{ab}$ initio parametrization of density functional dispersion correction (DFT-D) for the 94 elements H-Pu. J. Chem. Phys. 2010, 132 (15), 154104 DOI: 10.1063/1.3382344.

52. Roy, L. E.; Hay, P. J.; Martin, R. L. Revised basis sets for the LANL effective core potentials. J. Chem. Theory Comput. 2008, 4 (7), 1029-1031.

53. Ehlers, A. W.; Böhme, M.; Dapprich, S.; Gobbi, A.; Hoellwarth, A.; Jonas, V.; Koehler, K. F.; Stegmann, R.; Veldkamp, A.; Frenking, G. A set of f-polarization functions for pseudopotential basis sets of the transition metals $\mathrm{Sc}-\mathrm{Cu}, \mathrm{Y}-\mathrm{Ag}$ and $\mathrm{La}-\mathrm{Au}$. Chem. Phys. Lett. 1993, 208 (1-2), 111-114.

54. Hay, P. J.; Wadt, W. R. Ab initio effective core potentials for molecular orbital calculations - potentials for $\mathrm{K}$ to Au including the outermost core orbitals. J. Chem. Phys. 1985, 82 (1), 299-310 DOI: $10.1063 / 1.448975$.

55. Marenich, A. V.; Cramer, C. J.; Truhlar, D. G. Universal Solvation Model Based on Solute Electron Density and on a Continuum Model of the Solvent Defined by the Bulk Dielectric Constant and Atomic Surface Tensions. J. Phys. Chem. B 2009, 113 (18), 6378-6396 DOI: 10.1021/jp810292n.

56. Bryantsev, V. S.; Diallo, M. S.; Goddard, W. A., III. Calculation of solvation free energies of charged solutes using mixed cluster/continuum models. J. Phys. Chem. B 2008, 112 (32), 97099719 DOI: $10.1021 /$ jp802665d.

57. Tang, W.; Matyjaszewski, K. Effects of Initiator Structure on Activation Rate Constants in ATRP. Macromolecules 2007, 40 (6), 1858-1863.

58. Peng, C. H.; Kong, J.; Seeliger, F.; Matyjaszewski, K. Mechanism of Halogen Exchange in ATRP. Macromolecules 2011, 44 (19), 7546-7557 DOI: 10.1021/ma201035u.

59. Lanzalaco, S.; Fantin, M.; Scialdone, O.; Galia, A.; Isse, A. A.; Gennaro, A.; Matyjaszewski, K. Atom Transfer Radical Polymerization with Different Halides ( $\mathrm{F}, \mathrm{Cl}, \mathrm{Br}$, and $\mathrm{I}$ ): Is the Process "Living" in the Presence of Fluorinated Initiators? Macromolecules 2017, 50 (1), 192-202 DOI: 10.1021/acs.macromol.6b02286.
60. Nakazawa, H.; Kadoi, Y.; Mizuta, T.; Miyoshi, K.; Yoneda, H. A transition metal diaminophosphonate complex Synthesis and structure of (eta-5- $\left.\mathrm{C}_{5} \mathrm{H}_{5}\right)(\mathrm{CO})_{2} \mathrm{Fe}\left(\mathrm{P}(\mathrm{O})\left(\mathrm{NEt}_{2}\right)_{2}\right) \times 2 \mathrm{FeCl}_{2}$. J. Organomet. Chem. 1989, 366 (3), 333-342 DOI: 10.1016/0022$328 x(89) 87184-0$.

61. Döring, M.; Uhlig, E.; Dahlenburg, L. Biuclear reaction products of Grignard compounds and transition metal acetylacetonates - Catalysts of cross-coupling. Z. Anorg. Allg. Chem. 1989, 578 (11), 58-68 DOI: 10.1002/zaac.19895780107.

62. Pohl, S.; Opitz, U.; Saak, W.; Haase, D. Complexes of FeI2 and $\mathrm{FeI}_{3}$ with tetramethylurea. Z. Anorg. Allg. Chem. 1993, 619 (3), 608-612 DOI: 10.1002/zaac.19936190329.

63. Lorenz, I. P.; Maier, M.; Polborn, K. New organometalated phosphinato- $\mathrm{O}, \mathrm{O}$ ' ligands in the planar eight-membered ring $\{\mathrm{Cp}(\mathrm{CO})(2) \mathrm{Fe}\} \mathrm{tBuPO}(2) \mathrm{FeCl}(2)(2)$. Eur. J. Inorg. Chem. 2002, (2), 327-330.

64. Li, C. X.; Pattacini, R.; Braunstein, P. A fluorene-based diphosphinite ligand, its $\mathrm{Ni}, \mathrm{Pd}, \mathrm{Pt}, \mathrm{Fe}, \mathrm{Co}$ and $\mathrm{Zn}$ complexes and the first structurally characterized diphosphinate metal chelates. Inorg. Chim. Acta 2010, 363 (15), 4337-4345 DOI: 10.1016/j.ica.2010.06.007.

65. Gill, N. S. Complex halides of the transition metals. J. Chem. Soc. 1961, 3512-15 DOI: 10.1039/jr9610003512.

66. Gao, H. H.; Yan, C. H.; Tao, X. P.; Xia, Y.; Sun, H. M.; Shen, Q.; Zhang, Y. Synthesis of Anionic Iron(II) Complex Bearing an N-Heterocyclic Carbene Ligand and Its Catalysis for Aryl Grignard Cross-Coupling of Alkyl Halides. Organometallics 2010, 29 (18), 4189-4192 DOI: 10.1021/om100482w.

67. Fedushkin, I. L.; Skatova, A. A.; Khvoinova, N. M.; Lukoyanov, A. N.; Fukin, G. K.; Ketkov, S. Y.; Maslov, M. O.; Bogomyakov, A. S.; Makarov, V. M. New high-spin iron complexes based on bis(imino)acenaphthenes (BIAN): synthesis, structure, and magnetic properties. Russ. Chem. B. 2013, 62 (10), 2122-2131 DOI: 10.1007/s11172-013-0311-y.

68. Jana, B.; Hovey, M.; Ellern, A.; Pestovsky, O.; Sadow, A. D.; Bakac, A. Unusual structural motif in a zwitterionic Fe(II) complex of a tetradentate phosphine. Dalton Trans. 2012, 41 (41), 12781-12785 DOI: 10.1039/c2dt31437a.

69. Li, Z.; Liu, L.; Sun, H.-M.; Shen, Q.; Zhang, Y. Alkyl Grignard cross-coupling of aryl phosphates catalyzed by new, highly active ionic iron(II) complexes containing a phosphine ligand and an imidazolium cation. Dalton Trans. 2016, 45 (44), 17739-17747 DOI: 10.1039/c6dt02995g.

70. Gurewitz, E.; Shaked, H. Neutron diffraction study of the crystallographic and magnetic structures of potassium tribromoferrate(II) Acta Crystallogr. B 1982, 38 (NOV), 2771-2775 DOI: $10.1107 / \mathrm{s} 0567740882009923$.

71. Figgis, B. N.; Lewis, J. The magnetic properties of transition metal complexes. Prog. Inorg. Chem. 1964, 6, 37-239.

72. Shipp, D. A.; Wang, J. L.; Matyjaszewski, K. Synthesis of acrylate and methacrylate block copolymers using atom transfer radical polymerization. Macromolecules 1998, 31 (23), 8005-8008.

73. van Weert, G.; Shang, Y. X. Iron control in nitrate hydrometallurgy by (auto) decomposition of iron(II) nitrate. Hydrometallurgy 1993, 33 (3), 255-271 DOI: 10.1016/0304386x(93)90066-m. 


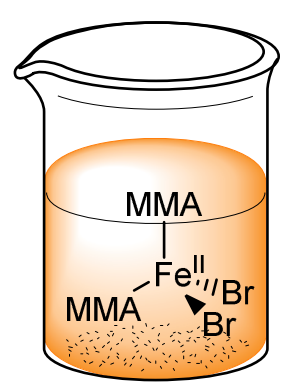

Inactive ATRP catalyst

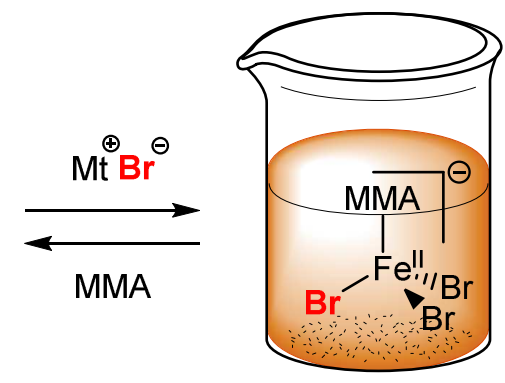

PMMA-Br
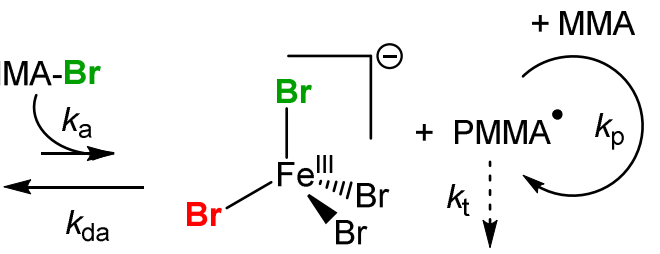

MMA polymerization terminations

Active ATRP catalyst 